
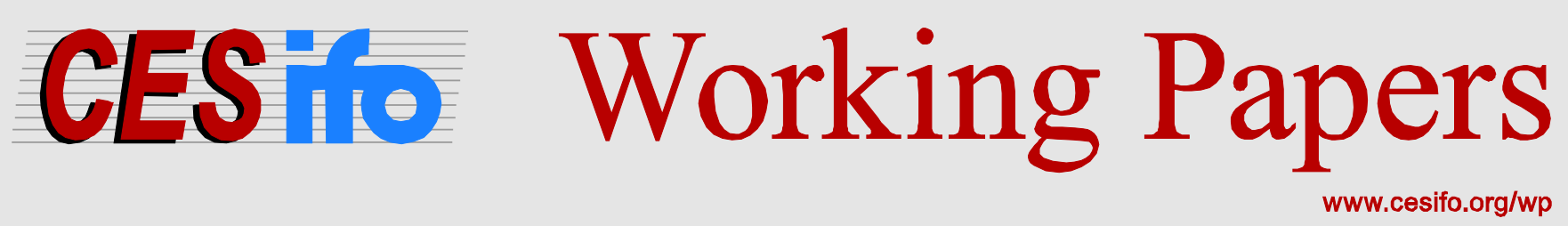

\title{
Are there Differences in the Effectiveness of Quantitative Easing at the Zero-Lower-Bound in Japan over Time?
}

\author{
Henrike Michaelis \\ Sebastian Watzka
}

\author{
CESIFO WORKING PAPER NO. 4901 \\ CATEGORY 7: MONETARY POLICY AND INTERNATIONAL FinANCE \\ JULY 2014
}
An electronic version of the paper may be downloaded
- from the SSRN website: Www.SSRN.com
- from the RePEc website: Www.RePEc.org
- from the CESifo website: www.CESifo-group.org/wp

\section{CESifo}




\title{
Are there Differences in the Effectiveness of Quantitative Easing at the Zero-Lower-Bound in Japan over Time?
}

\begin{abstract}
Using a time-varying parameter vector autoregression (TVP-VAR) with a new sign restriction framework, we study the changing effectiveness of the Bank of Japan's Quantitative Easing policies over time. We analyse the Zero-Interest Rate Policy from 1999 to 2000, the Quantitative Easing Policy from 2001 to 2006, and most recently the 'Abenomics' monetary policy easing strategy. Our results indicate that there are important differences concerning the effects of Quantitative Easing over time. We find a stronger and longer lasting positive influence of QE shocks on real GDP and CPI especially since 2013. This might reflect the influence of the 'Abenomics' program.
\end{abstract}

JEL-Code: C300, E440, E520, F410.

Keywords: Bayesian time-varying parameter VAR, monetary policy, quantitative easing, zero lower bound.

\author{
Henrike Michaelis \\ Department of Economics \\ University of Munich \\ Ludwigstrasse 28 \\ Germany - 80539 Munich \\ Henrike.Michaelis@econ.Imu.de
}

\author{
Sebastian Watzka \\ Department of Economics \\ University of Munich \\ Ludwigstrasse 28 \\ Germany - 80539 Munich \\ Sebastian.Watzka@econ.Imu.de
}

Date: June 2014 


\section{INTRODUCTION}

Using a time-varying parameter vector autoregression (TVP-VAR) framework, we study the changing effectiveness of the Bank of Japan's Quantitative Easing policies over time. It is well known that the Japanese economy has been stuck in a liquidity trap since the mid-90s. Since then the Bank of Japan (BoJ) has adopted various different strategies to combat the recession and stimulate the economy. We use a time-varying VAR framework with stochastic volatility to analyse how the effects of a Quantitative Easing (QE) shock have changed over time and when it was possibly effective.

We specifically analyse the so-called Zero-Interest Rate Policy (ZIRP) from 1999 to 2000, the Quantitative Easing Policy (QEP) from 2001 to 2006, and most recently the so-called 'Abenomics' monetary policy easing strategy implemented under current BoJ Governor Haruhiko Kuroda and carried out under the political leadership of Prime Minister Shinzo Abe.

To identify a QE shock, we follow Schenkelberg and Watzka (2013) and use a new sign restriction approach when the economy is stuck at the Zero Lower Bound (ZLB). To allow for time variation in the impulse responses, we embed this identification strategy in the TVP-VAR framework of Primiceri (2005). With this approach we are seeking to shed light on the changing nature of the monetary policy transmission mechanism in Japan during these different monetary policy stances.

We investigate whether the impact of a QE shock has varied over time in Japan through a marginal likelihood estimation which compares a constant coefficient VAR with our TVP-VAR. Our research confirms that the TVP-VAR is indeed a better fit for Japan and that a QE shock estimated for the Japanese economy does in fact have changing effects over time. In particular it seems that the effects on both real GDP and core CPI have become stronger and longer lasting over time. More specifically, the response for prices in 2013, a period probably highly influenced by the 'Abenomics' program, stays permanently significant. This is in contrast to the responses under the ZIRP and the first QE program. During these periods only an initial significant effect is observed. Regarding GDP, we estimate again a significant impact during the time of the 'Abenomics' strategy, whereas during the ZIRP and the first QE program no significant impact is reported. Generally, these findings are also supported by our variance decomposition analysis. Especially since 2013, the relative importance of QE shocks has increased. These effects are likely to be driven by some extent by the current 'Abenomics' program. 
Our results are interesting not only for Japan, but also for other advanced economies with nominal interest rates close to zero or at the ZLB. The recent financial crisis has by now been going on for five years, by some already labeled as 'Great Recession'. It started with housing market bubbles bursting in the US, UK, and some Euro Area countries. Problems in highly leveraged banking sectors followed, and policy interest rates were subsequently lowered to historically low levels of virtually zero. A severe deleveraging of the private sector is currently hitting the real economy of most advanced countries. Inflationary pressure has generally been subdued. Hence, the current experiences of most advanced economies pretty closely mirror the Japanese experience. It is against this background that our study on the effectiveness of the QE policy in Japan sheds light on the potential effects of recently implemented QE policies in the US, the UK, and possibly the Euro Area.

The remainder of the paper is organised as follows: Section 2 gives an overview of related literature on Japan, Section 3 quickly summarises the Japanese monetary policy developments, Section 4 describes the setup of our empirical model, Section 5 briefly summarises the marginal likelihood results and Section 6 discusses our results. It is divided into the four following subsections. Subsection one presents our results on a QE shock. Subsection two briefly reports the effect of other business cycle disturbances. Subsection three outlines results on a forecast error variance decomposition (FEVD) and subsection four links our results to the underlying theoretical framework of Eggertsson (2011). Section 7 discusses our robustness checks and section 8 finally concludes.

\section{SuRvey of Related Literature for JAPAN}

Vector autoregression models (VAR) are a widely used tool for analysing the monetary policy transmission, also for Japan. These include for example Miyao (2002), who introduces the benchmark VAR model for estimating the impact of monetary policy during 1975 to 1998. Since it is likely that the transmission mechanism varies over time, more flexible models, accounting for time variation, are becoming increasingly a focus of research. For example, Kimura et al. (2003) estimate a VAR with time-varying coefficients for the period between 1971 and 2002. Still, their approach relies on a constant variance. In contrast, Nakajima (2011) employs a time-varying VAR (TVP-VAR) and allows for stochastic volatility in the variance covariance matrix. ${ }^{1}$

An important issue which is increasingly being discussed in the literature, is the monetary policy transmission when nominal interest rates are close to zero or even at the Zero Lower

\footnotetext{
${ }^{1}$ His sample is based on data ranging from 1977Q1 until 2007Q4. Following an increase in the call rate, he reports a fall in prices until the mid 90 s and thereafter a small price puzzle. Further, he finds a visible effect on output.
} 
Bound (ZLB). In these situations, central banks have only very little room for decreasing their short-term policy rates. Therefore, the impact of monetary policy is unlikely to operate through the conventional interest rate channel. Instead central banks then typically operate through what is now called 'forward guidance' or increases in the monetary base through some form of 'Quantitative Easing' (QE). Within the VAR framework, several papers deal explicitly with the ZLB for Japan and investigate the monetary policy transmission during these periods. Fujiwara (2006) uses a Markov switching VAR model for the period of 1985 to 2004 to investigate whether there are structural breaks in the impact of monetary policy due to the introduction of the zero nominal interest rate. Kamada and Sugo (2006) estimate a monetary policy proxy which can take on negative values to account for a whole range of different policy measures. Iwata and Wu (2006) model the nominal interest rate as a censored variable in a VAR model with constant coefficients. Nakajima et al. (2011) employ a TVP-VAR with stochastic volatility and in addition consider the nominal interest rate to be a censored variable.

It should be noted that since the beginning of 2001, the BoJ does not use the call rate as their operating target but the outstanding current account balances held by banks at the BoJ. Since this measure is the key monetary instrument in Japan, it is of importance to learn about its effectiveness. For example, Kimura et al. (2003), Kimura and Nakajima (2013) and Hayashi and Koeda (2014) trace the effect of such a QE shock. Hayashi and Koeda (2014) employ a regime switching SVAR for the period from 1988 until 2012 and find a visible effect on output and inflation following a QE shock. In contrast are the findings by Kimura et al. (2003) and Kimura and Nakajima (2013). Kimura et al. (2003) use a TVP-VAR with a constant variance from 1985Q2 until 2002Q1. For the ZLB periods they do not estimate a significant effect on output and prices. Kimura and Nakajima (2013) employ a TVP-VAR with stochastic volatility and combine it with a latent threshold model from 1981Q2 until 2012Q3. Following a QE shock, they also report a non-visible effect on both output and inflation. However, these studies use a recursive identification scheme for identifying a QE shock. As it is generally argued, this can be rather restrictive especially in a model with quarterly data. By referring to sign restrictions, usually less restrictions need to be imposed. For example, Kamada and Sugo (2006) and Franta (2011) incorporate sign restrictions to identify an unconventional monetary policy shock at the ZLB for Japan. Kamada and Sugo (2006) use Uhlig (2005)'s sign restricted VAR together with a special 'intermediate' monetary policy variable which is not a proper monetary policy instrument like the call rate or base money, but still closely related to the monetary policy instrument. Their sample spans from 1978 to April 2005. Franta (2011) uses the TVP-VAR with stochastic volatility but with altering sign restrictions to account for differences in the conduct of monetary policy in Japan 
between 1981 and 2010. He finds differences in the monetary policy transmission between the QE policy period and 'normal' times. However, he does not report visible differences to a QE shock during the ZLB periods. Note that he only identifies the monetary policy shock. This may not be sufficient since it does not ensure that other disturbances, such as e.g. business cycle fluctuations (demand or supply shocks), enter the identified monetary policy shock. Moreover, he does not capture the recent influence of the 'Abenomics' strategy. Against the background of still rather scarce empirical evidence on the recent period in Japan, it is crucial to provide more details on the monetary policy transmission. ${ }^{2}$

We hope to fill these gaps. More specifically, we use a relatively agnostic framework for analysing QE shocks when interest rates are close to zero. We employ a novel identification scheme based on sign restrictions to incorporate the ZLB of short-term nominal interest rates. These sign restrictions were introduced by Schenkelberg and Watzka (2013) in a BVAR to identify a QE shock when the economy is stuck at the ZLB. ${ }^{3}$ Next to the QE shock, two business cycle disturbances, a demand and a supply shock, are identified for two reasons: (1) for avoiding that business cycle disturbances enter the identified QE shock and (2) for evaluating the quantitative importance of the $\mathrm{QE}$ shock relative to the business cycle shocks and how they have changed across time. Our estimation is based on the TVP-VAR with stochastic volatility, introduced by Primiceri (2005). Among others, Nakajima (2011) underlines the importance to allow for time variation. Also our analysis confirms the importance of a time-varying approach by means of a marginal likelihood comparison. Furthermore, as far as we are aware, this work is the first one to address the influence of a QE shock on key macro economic variables during the 'Abenomics' period. based on a VAR setting. Interestingly, the effectiveness of unconventional monetary policies ${ }^{4}$ has been extensively studied on financial market effects, but there exists only a small body of empirical literature on real economic influences. It is against these backgrounds that our paper provides new interesting insights, not only for Japan, on the macro economic effects of QE shocks and whether they vary over time.

\footnotetext{
${ }^{2}$ See Hausman and Wieland (2014) for an exception

${ }^{3}$ This identification scheme is based on the New Keynesian model of Eggertsson (2011). See Appendix section D for a summary on the most important aspects of the Eggertsson model.

${ }^{4}$ Note, our focus is on the influence of $\mathrm{QE}$ as to other non-standard measures of unconventional monetary policy tools. The literature (see e.g. Bernanke and Reinhart (2004) and Bernanke et al. (2004) among others) generally divides unconventional monetary policy tools into three categories: (1) commitment to future policy stances, (2) QE, and (3) credit easing. A combination of these tools defines the term unconventional monetary policy.
} 


\section{Overview of Japanese Monetary Policy Developments}

This section briefly reviews the key developments of Japanese monetary policy over the last two decades. For a thorough discussion please refer to Mikitani and Posen (2000), Ugai (2007) and Ueda (2012). The bursting of the Japanese stock market bubble and the accompanying period of economic distress can be seen in Figure 1. The stock market was rising dramatically until around 1990. This went together with a rapid increase in industrial production under fairly low and constant rates of inflation. Realising that the elevated stock and land prices seemed out of touch with fundamentals the BoJ did in fact continuously increase the call rate.

Optimism turned into pessimism around 1990/1991 with both stock and land prices starting to fall rapidly. The Japanese economy was finally falling into deep recession. Japan had entered what is by now labeled 'Japan's lost decade'. Whilst Japanese GDP grew by an average rate of $3.9 \%$ per year in the pre-1991 period, growth slowed down to only $0.8 \%$ post-1991. Meanwhile the usually low Japanese unemployment rate more than doubled while the core inflation rate steadily trended below zero since 2000 .

The initial response of the BoJ to the bursting of the asset price bubbles and the recession

Figure 1. Industrial Production, Consumer Price Index and NIKKEI Stock Index

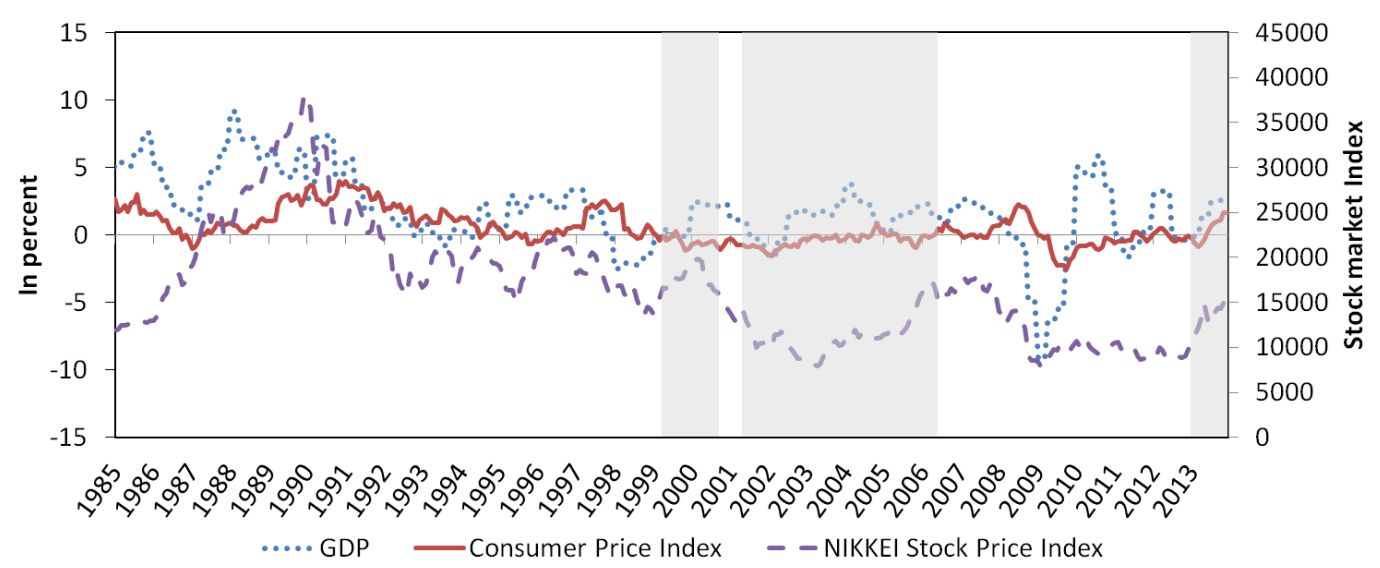

Shaded areas: 1999-2000 ZIRP, 2001-2006 1st QE period, 2013-end 'Abenomics' period

was rather slow and not very aggressive (Jinushi et al., 2000). In fact, Figure 2 shows that the call rate was high until 1992/1993 and decreased only very gradually until it reached $0.5 \%$ in the course of 1995 .

From February 1999 to August 2000, the BoJ officially introduced its so-called 'Zero Interest Rate Policy' (ZIRP) when it lowered the call rate to $0.03 \%$ (see Figure 2). It also tried to steer market expectations by adding commitments to its policy statements indicating 
FiguRE 2. Bank of Japan Short- and Long-Term Interest Rates

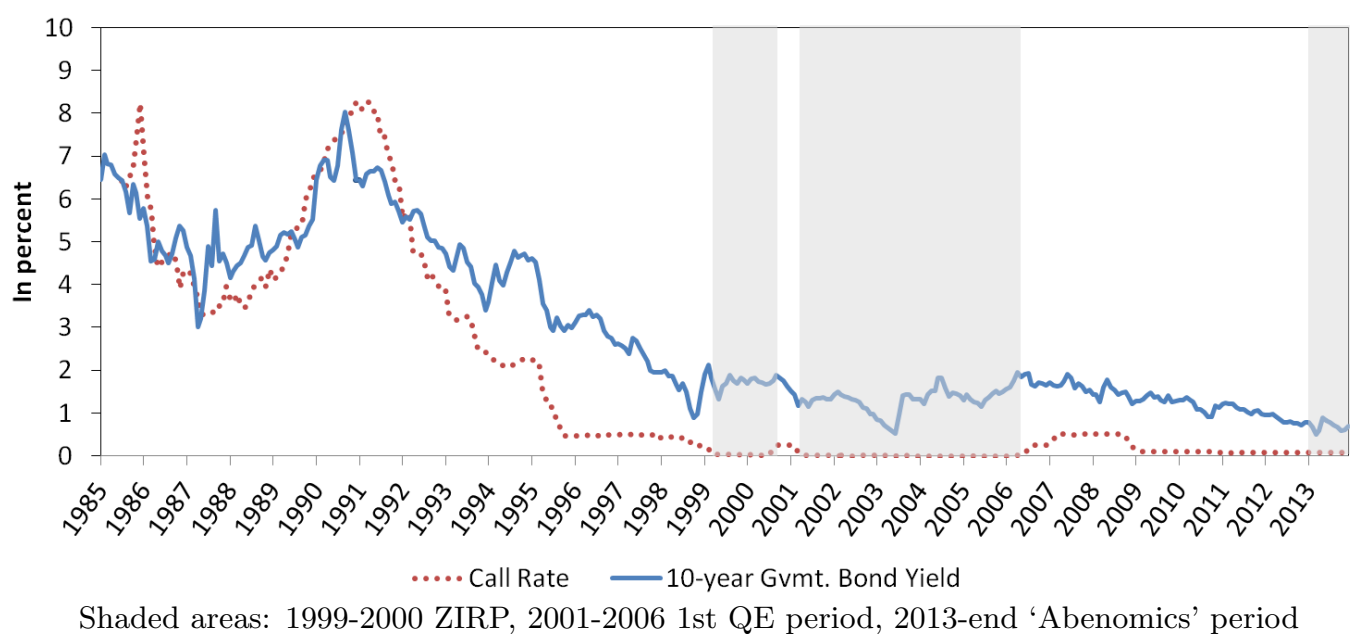

that it would keep the call rate low for a longer time.

After a short-lived economic recovery and following the worldwide bursting of the IT-stock market bubbles, the BoJ introduced a more aggressive policy program. From March 2001 until March 2006 it implemented the so-called 'Quantitative Easing Policy' (QEP) which consisted of three main elements: (i) the operating target was changed from the call rate to the outstanding current account balances held by banks at the BoJ, ${ }^{5}$ (ii) to commit itself to continue providing ample liquidity to banks until inflation stabilised at $0 \%$ or a slight increase, and (iii) to increase the amount of outright purchases of long-term Japanese government bonds. ${ }^{6}$ The monetary development and the effect of the BoJ's QEP measures can be seen in Figure 3. We plot that part of the monetary base that relates to the current account holdings of banks at the BoJ. The figure shows the enormous increase in those reserves during the QEP period and later again when the recent financial crisis hit. At the same time the figure plots the evolution of the broader monetary aggregate M2 which can be seen not to be reacting in any obvious manner to the increases in bank reserves.

Most recently, the Bank of Japan implemented its part of the so-called 'Abenomics' program. 'Abenomics' essentially stands for a broader package of three different policy measures (also called the three arrows): monetary policy, fiscal policy and structural reforms of goods and labor markets. Concerning the arrow of monetary policy, Shinzo Abe, after having been elected prime minister in December 2012, appointed Haruhiko Kuroda as BoJ

\footnotetext{
${ }^{5}$ Current account holdings is the technical label for Japanese bank reserves being held at the BoJ.

${ }^{6}$ See the thorough survey by Ugai (2007) for more details.
} 
Figure 3. Monetary Aggregates in Japan

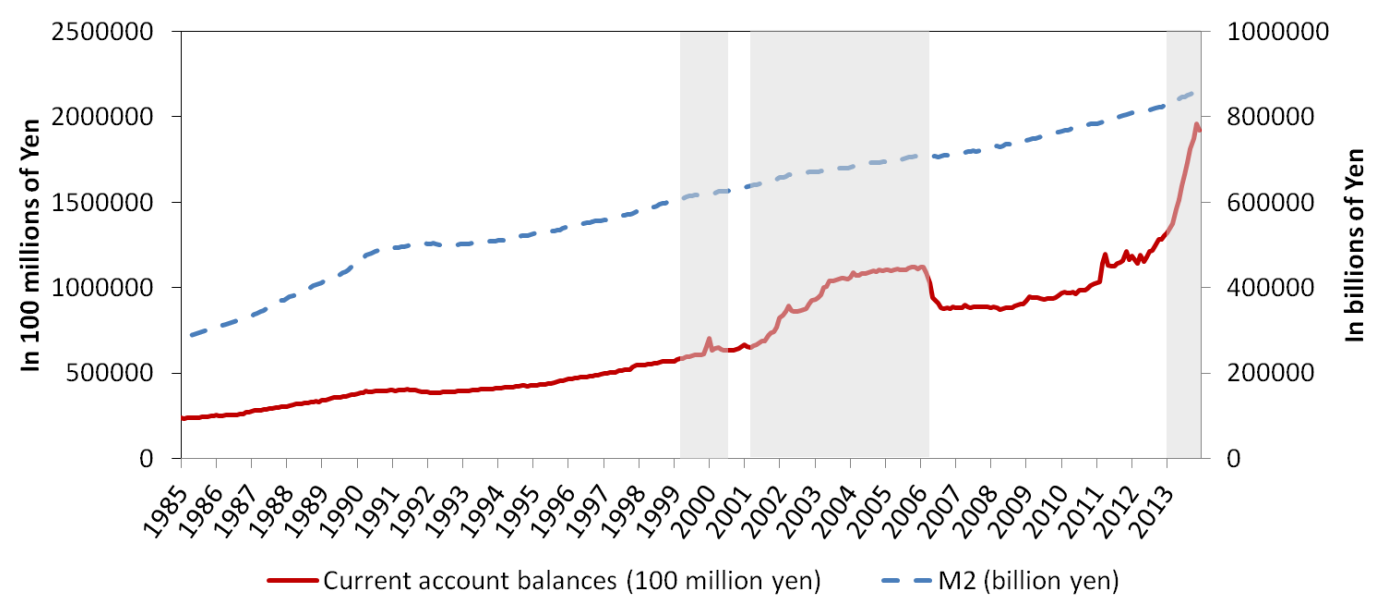

Shaded areas: 1999-2000 ZIRP, 2001-2006 1st QE period, 2013-end 'Abenomics' period

Governor in March 2013.

The most important monetary policy decision was then to raise the BoJ's inflation target from 1 to $2 \%{ }^{7}$ The BoJ then basically committed itself to achieving this inflation target as soon as possible and not later than within two years. This was officially phrased in the BoJ's 'Quantitative and Qualitative Monetary Easing' policy statement which laid out the details of how the new inflation target is going to be implemented. Essentially, the BoJ will conduct money market operations so that the monetary base will increase at an annual pace of about 60-70 trillion yen. Further specifics are a maturity extension of the BoJ's holdings of Japanese Government Bonds and its commitment to continue expanding the monetary base until inflation stabilises at its $2 \%$ target. Although the preliminary evaluation of this much more expansionary monetary policy stance is widely regarded as supportive for the growth stimulus to the Japanese economy, it is unclear how these measures will play out in the medium and longer run (see also Hausman and Wieland (2014) for a preliminary evaluation of 'Abenomics').

Having these macroeconomic and monetary developments in mind we next present our identification strategy based on the reasonable assumption that the BoJ since 1995 did not conduct its monetary policy through the call rate anymore - which was constrained by the ZLB - but by changing the reserve holdings of banks at the BoJ.

\footnotetext{
${ }^{7}$ The BoJ previously was given an inflation target of $1 \%$ in February 2012.
} 


\section{EMPIRICAL MODEL}

We use the TVP-VAR model with stochastic volatility to trace the reaction of key economic variables to QE shocks over time. Our empirical approach closely follows Primiceri (2005) and Nakajima (2011). ${ }^{8}$ The advantage of this framework is its flexibility to deal with the changing nature of the monetary transmission mechanism. This is particularly important for a country like Japan where monetary policy underwent significant changes in its stances.

The TVP-VAR model has both time-varying coefficient matrices as well as time-varying covariance matrices. The varying coefficients account for possible nonlinearities or timevariation in the lag structure of the model and the varying variance covariance matrices capture possible heterosecedasticity of the shocks and nonlinearities in the simultaneous relationships among the variables.

We estimate the following VAR model:

$$
y_{t}=c_{t}+B_{1, t} y_{t-1}+\ldots+B_{l, t} y_{t-l}+u_{t}, \quad t=1, \ldots, T
$$

where $y_{t}$ is a $n \times 1$ vector of endogenous variables; $c_{t}$, is a $n \times 1$ vector of time-varying intercepts; $B_{i, t}$, is a $n \times n$ matrix of time-varying coefficients with lag length $i=1, \ldots, l$; and $u_{t}$, is a $n \times 1$ vector of residuals. $\Omega_{t}$ describes the time-varying covariance matrix of $u_{t}$, which can be decomposed into:

$$
\operatorname{VAR}\left(u_{t}\right) \equiv \Omega_{t}=A_{t}^{-1} \Sigma_{t} \Sigma_{t}^{\prime}\left(A_{t}^{-1}\right)^{\prime} .
$$

Where $A_{t}$ is a time-varying lower triangular matrix and $\Sigma_{t}$ is a diagonal time-varying covariance matrix:

$$
A_{t}=\left[\begin{array}{cccc}
1 & 0 & \ldots & 0 \\
\alpha_{21, t} & 1 & \ddots & \vdots \\
\vdots & \ddots & \ddots & 0 \\
\alpha_{n 1, t} & \ldots & \alpha_{n(n-1), t} & 1
\end{array}\right] \quad \Sigma_{t}=\left[\begin{array}{cccc}
\sigma_{1, t} & 0 & \ldots & 0 \\
0 & \sigma_{2, t} & \ddots & \vdots \\
\vdots & \ddots & \ddots & 0 \\
0 & \ldots & 0 & \sigma_{n, t}
\end{array}\right]
$$

The time-varying VAR can then be rewritten as:

$$
\begin{gathered}
y_{t}=X_{t}^{\prime} \tilde{B}_{t}+A_{t}^{-1} \Sigma_{t} \varepsilon_{t}, \\
X_{t}^{\prime}=I \bigotimes\left[1, y_{t-1}^{\prime}, \ldots, y_{t-l}^{\prime}\right],
\end{gathered}
$$

where $\tilde{B}_{t}$ is a stacked vector containing all coefficients of the right hand side of equation 4.1. $\operatorname{VAR}\left(\varepsilon_{t}\right)=I_{n}$ and the operator $\otimes$ denotes the Kronecker product.

\footnotetext{
${ }^{8}$ Further related studies are Franta (2011) and Canova and Ciccarelli (2009).
} 
The dynamics of the time-varying parameters $\left(B_{t}\right.$ and $\left.A_{t}\right)$ are following a driftless random walk, whereas the covariance matrix $\left(\Sigma_{t}\right)$ evolves as a geometric driftless random walk:

$$
\begin{array}{r}
B_{t}=B_{t-1}+\nu_{t}, \\
\alpha_{t}=\alpha_{t-1}+\xi_{t}, \\
\log \sigma_{t}=\log \sigma_{t-1}+\eta_{t},
\end{array}
$$

where $\alpha_{t}$ is a stacked vector of the lower triangular coefficients of the matrix $A_{t}$ and the standard deviation $\sigma_{t}$ is the vector of the diagonal elements of the matrix $\Sigma_{t}$. The vector of innovations $\left[\varepsilon_{t}^{\prime}, \nu_{t}^{\prime}, \xi_{t}^{\prime}, \eta_{t}^{\prime}\right]$ is assumed to be jointly normally distributed with variance-covariance matrix:

$$
V A R\left(\varepsilon_{t}, \nu_{t}, \xi_{t}, \eta_{t}\right)=\left[\begin{array}{cccc}
I_{n} & 0 & 0 & 0 \\
0 & Q & 0 & 0 \\
0 & 0 & S & 0 \\
0 & 0 & 0 & W
\end{array}\right]
$$

where $I_{n}$ is an $n$ dimensional identity matrix and $Q, S$ and $W$ are positive definite matrices. $S$ is assumed to be block diagonal and in order to reduce the dimensionality of the estimation, we restrict $W$ to be a diagonal matrix.

\subsection{Priors.}

For evaluating posteriors, prior distributions need to be specified. For the calibration of these priors, we use a training sample based on the period from 1980Q1 to 1995Q4 (see Appendix A) and run an OLS estimation on a fixed-coefficient VAR model.

The $O L S$ point estimates $\left(\hat{B}_{O L S}\right)$ and four times their variance specify the mean and the variance of $B_{0}$. We assume the same specification for the prior distribution of the simultaneous relation matrix $A_{0}$. The prior mean for the log standard errors is the log of the $O L S$ point estimates $\left(\hat{\sigma}_{O L S}\right)$, and the prior covariance matrix is specified to be $4 \cdot I_{n}$. The priors for the initial states of the time-varying VAR-parameters $B_{0}, A_{0}$ and $\log \sigma_{0}$ follow a normal distribution. The hyperparameters $Q, S$ and $W$ are the covariance matrices of the innovations (see equations 4.5, 4.6 and 4.7). Matrices $Q$ and $S$ are distributed as an independent inverseWishart and $W$ is assumed to follow a inverse-Gamma prior distribution. In summary: 


$$
\begin{aligned}
B_{0} & \sim N\left(\hat{B}_{O L S}, 4 \cdot V\left(\hat{B}_{O L S}\right)\right) \\
A_{0} & \sim N\left(\hat{A}_{O L S}, 4 \cdot V\left(\hat{A}_{O L S}\right)\right), \\
\log \sigma_{0} & \sim N\left(\hat{\sigma}_{O L S}, 4 \cdot I_{n}\right) \\
Q & \sim I W\left(k_{Q}^{2} \cdot \tau \cdot V\left(\hat{B}_{O L S}\right), \tau\right), \\
W & \sim I G\left(k_{W}^{2} \cdot(1+\operatorname{dim}(W)) \cdot I_{n},(1+\operatorname{dim}(W))\right), \\
S_{b} & \sim I W\left(k_{S}^{2} \cdot\left(1+\operatorname{dim}\left(S_{b}\right)\right) \cdot V\left(\hat{A}_{b, O L S}\right),\left(1+\operatorname{dim}\left(S_{b}\right)\right)\right),
\end{aligned}
$$

where $\tau$ has the size of the training sample, $S_{b}$ with the index $b$ refers to the corresponding blocks of a particular equation and $\hat{A}_{b, O L S}$ denotes the respective blocks of $\hat{A}_{O L S} \cdot{ }^{9}$ The degrees of freedom for $W$ and $S_{b}$ are specified as one plus its respective matrix dimension. The size of the training sample defines the degrees of freedom for $Q$. Finally, the parameters $k_{Q}=0.01, k_{W}=0.1$ and $k_{S}=0.01$ define prior beliefs about the degree of time variation in the parameters, covariances and volatilities. For example, for the OLS estimation of the covariance matrix of the VAR coefficients, we allow for $1 \%\left(k_{Q}=0.01\right)$ of uncertainty surrounding the $V\left(\hat{B}_{O L S}\right)$ estimates to time variation (Kirchner et al. (2010)). ${ }^{10}$

We conduct a formal model selection since there are no economic reasons for choosing one $\left(k_{Q}, k_{W}, k_{S}\right)$ combination over another. Posterior probabilities for a set of 18 models are estimated based on the reversible jump Markov chain Monte Carlo (RJMCMC) method (see Primiceri (2005)). ${ }^{11}$ The selection of $k_{Q}, k_{W}$ and $k_{S}$ delivers a posterior probability for one combination which is almost one. Table 9 in the Appendix $\mathrm{C}$ reports the posterior probability estimates for the set of 18 models.

\subsection{Identification and Estimation.}

So far, we have outlined the estimation strategy for a reduced form VAR which is estimated using Bayesian methods for the sample from 1996:Q1 to 2013:Q4. For maintaining the degrees of freedom, two lags are used. For approximating the posterior distribution, 40, 000 iterations of the Gibbs sampler are used and we drop the first 20, 000 iterations for convergence. For breaking the autocorrelation of the draws, only every $10 t h$ iteration is kept. Our final estimates are therefore based on 2,000 iterations. The sample autocorrelation functions of the draws die out rather quickly. Furthermore, the convergence diagnostics

\footnotetext{
${ }^{9}$ The system consists of three blocks with the respective size: 2,3 and 4 .

${ }^{10}$ As a sensitivity check, we also experimented with other value combinations of these coefficients. The responses obtained are robust to those presented.

${ }^{11}$ The set of 18 models are constructed from all possible combinations of $k_{Q}=\{0.01 ; 0.05 ; 0.1\}, k_{W}=$ $\{0.001 ; 0.01\}$ and $k_{S}=\{0.01 ; 0.025 ; 0.1\}$.
} 
reveal satisfactory results. ${ }^{12}$

To identify a QE shock, we follow Schenkelberg and Watzka (2013) and use their sign restriction approach when the economy is stuck at the ZLB. Essentially the idea is to let the variables of interest, in particular real GDP, unrestricted, whilst imposing relatively mild sign restrictions on the remaining variables. In addition to real GDP, the real effective exchange rate is left unrestricted as it might give us some indication of whether QE works through depreciation and the stimulating effects on exports. The sign restriction to identify the QE shock is imposed on bank reserves held at the BoJ, which have been the key monetary operating instrument of the central bank since 2001. More specifically, a QE shock is defined as a $1 \%$ increase in bank reserves. We restrict the price level to respond non-negatively to a positive QE shock. Since the price level is empirically known to move sluggishly, we also allow for a zero impact effect. ${ }^{13}$

In addition to the QE shock, we identify two business cycle disturbances: a positive demand and a positive supply shock. These are identified for two reasons: (1) to avoid that disturbances in business cycle fluctuations enter the identified QE shock and (2) to evaluate the explanatory power of the QE shock relative to the demand and supply shocks. The aggregate demand and supply shocks are identified according to the New Keynesian predictions of an economy at the ZLB (see Appendix D for a short overview of the Eggertsson (2011) model). ${ }^{14}$ All sign restrictions are binding for three quarters after the shock. Table 1 summarises the restrictions.

For implementing the sign restrictions, we slightly modify the model specified in equations 4.4-4.7. So far, it is based on the recursive identification. We additionally specify an orthonormal rotation matrix $G_{t}$, i.e., $G_{t}^{\prime} G_{t}=I_{n}$. The model in equation 4.4 can then be rewritten as

$$
y_{t}=X_{t}^{\prime} \tilde{B}_{t}+A_{t}^{-1} \Sigma_{t} G_{t}^{\prime} G_{t} \varepsilon_{t}=X_{t}^{\prime} \tilde{B}_{t}+A_{t}^{-1} \Sigma_{t} G_{t}^{\prime} \tilde{\varepsilon}_{t}
$$

\footnotetext{
12 A detailed overview can be obtained upon request.

13 Ideally, we would include more variables to shed more light on the transmission mechanism, but are limited here by degrees of freedom problems from our estimation method.

${ }^{14}$ Because the main focus in this study is on the effects of QE on the macro economy, we will not go into a detailed discussion of any of the other shocks here. For a thorough overview of the demand and supply shocks, please refer to Eggertsson (2011) and Schenkelberg and Watzka (2013). For a brief summary on the identification strategy of the demand and supply shocks, refer to Appendix D.1.
} 
TABle 1. Sign Restrictions

\begin{tabular}{ccccc}
\hline \hline & \multicolumn{5}{c}{ QE Shock } & DE Shock & SP Shock \\
\hline Impact & 0 & & \\
Prices & $K=3$ & $\geq$ & $>$ & $\leq$ \\
\hline GDP & $K=3$ & $?$ & $\geq$ & $<$ \\
\hline Reserves & $K=3$ & $>$ & $?$ & $?$ \\
\hline Exchange Rate & $K=3$ & $?$ & $?$ & $?$ \\
\hline Further restriction & $K=3$ & & $\left|\frac{\text { GDP }}{\text { CPI }}\right|>1$ & $\left|\frac{\text { GDP }}{\text { CPI }}\right|<1$ \\
\hline \hline
\end{tabular}

Note: ? denotes no restriction, $>$ defines a positive effect of the respective shock on the variable, vice versa for $<. K=3$ indicates that the restriction horizon is three quarters. $|\mathrm{GDP} / \mathrm{CPI}|$ denotes the absolute value of the ratio between the GDP response and the CPI response.

$\tilde{\varepsilon}_{t}=G_{t}^{\prime} \varepsilon_{t}$ denotes the new shocks and the respective variance is $\operatorname{Var}\left(\tilde{\varepsilon}_{t}\right)=G_{t} I_{n} G_{t}^{\prime}$. We use the QR decomposition for finding $G_{t}$. Since we have a four variable VAR, $G_{t}$ is a 4 x 4 matrix:

$$
G_{t}=\left(\begin{array}{ccc}
Q R(\theta[1,1]) & \ldots & Q R(\theta[1,4]) \\
\vdots & \ddots & \vdots \\
Q R(\theta[4,1]) & \ldots & Q R(\theta[4,4])
\end{array}\right)
$$

In a first step we draw a $4 \times 4$ matrix, $\theta$, from the $N(0,1)$ distribution. Step two: we take the QR decomposition of $\theta$ and construct the $G_{t}$ matrix. This algorithm calculates a candidate structural impact matrix. Step three: it is checked whether this matrix is in line with the sign restrictions. Step four: if it satisfies the restrictions it is stored. Otherwise another $\theta$ is drawn from the standard normal distribution and we repeat the procedure from step two.

\section{Empirical Evidence of Time Variation in Japan: is there any?}

As a first step, we search for formal econometric evidence on whether the impact of a QE shock in Japan has changed across time. In particular, we calculate marginal likelihood estimates for a traditional constant-coefficient VAR model and our time-varying parameter (TVP-VAR) model with stochastic volatility. ${ }^{15}$ The model that yields the largest marginal likelihood fits the given data best. We follow Nakajima et al. (2011) and use the modified harmonic mean estimator of the marginal likelihood due to Geweke (1999). ${ }^{16}$ The log marginal likelihood value for the TVP-VAR, -557.5, is higher than the marginal likelihood estimate for the constant VAR, -700.062, suggesting that the TVP-VAR model with stochastic volatility

\footnotetext{
${ }^{15}$ Prior for the constant parameter VAR: $B \sim N(0,4 \times I), \alpha \sim N(0,4 \times I), \sigma^{-1} \sim \operatorname{Gamma}(2,0.02)$

${ }^{16}$ For a detailed description of the harmonic mean estimator, please refer to Nakajima et al. (2011). The marginal likelihood calculation is based on the priors and number of lags as specified above. Additionally, we have to specify the parameter $\tau$. We follow Nakajima et al. (2011) and set $\tau=0.99$.
} 
is indeed a better model for Japan than the constant VAR.

\section{Results of the TVP-VAR}

In what follows, section 6.1 presents the estimated median impulse responses of the QE shock (see also Appendix E). A key focus is on the different effects following the same QE shock over the different monetary policy stances of the BoJ during the entire ZLB period. It also includes an analysis on the posterior probability for the difference in the impulse responses. Section 6.2 shortly summarises the key findings of the demand and supply shocks. For evaluating the quantitative importance of the QE shock relative to the two business cycle disturbances, we present a forecast error variance decomposition (FEVD) in section 6.3. Section 6.4 briefly links our results to the theoretical framework of Eggertsson (2011) and in the Appendix section $G$, the time-varying posterior estimates of the covariance matrix are presented.

\subsection{Impulse Responses to Quantitative Easing Shocks.}

Figure 4 presents the median impulse responses (over 17 quarters and the time period: 1996:1-2013:4) to a 1\% increase in reserves in the given period across the sample.

We clearly see that a QE shock has time-varying effects. Regarding the effect of a $\mathrm{QE}$ shock on prices, they exhibit time variation across our sample. The response of prices has been restricted to increase for three quarters following the QE shock, so the immediate rise is by construction (Figure 4a). The positive impact seems to be significant after four quarters and for eight quarters from 2006 onwards (Figures 13a and 13b in Appendix E plot the evolution of the responses at the 4 th and 8 th quarter with percentiles). ${ }^{17}$ The long run impact on prices appears to change across our sample. More specifically, during the ZIRP from 1999 to 2000, the cumulative effect on prices seems to be close to $0.05 \%$ after three years. Since 2000, the long run impact seems to strongly decrease in size. Note that in August 2000 the ZIRP ended. From 2002 onwards, the long run impact appears to increase again. This effect may mirror the introduction of the first QE program in 2001. In 2003Q3 the effect on prices stand at about $0.15 \%$ after three years. Overall, our results suggest that the changes in the transmission mechanism of a QE shock may capture the end of the ZIRP and the beginning of the first QE program respectively. It is very likely that these monetary

\footnotetext{
17 These figures give the 16th and 84th percentiles of the posterior distribution of the impulse responses as these confidence bands are standard in the literature. Based on the normality assumption, these percentiles refer to one-standard error bands (see also Uhlig (2005)).
} 
policy decisions influenced the economy. ${ }^{18}$

Figure 4. Time-Varying Impulse Responses to a Monetary Policy Shock

(A) Prices

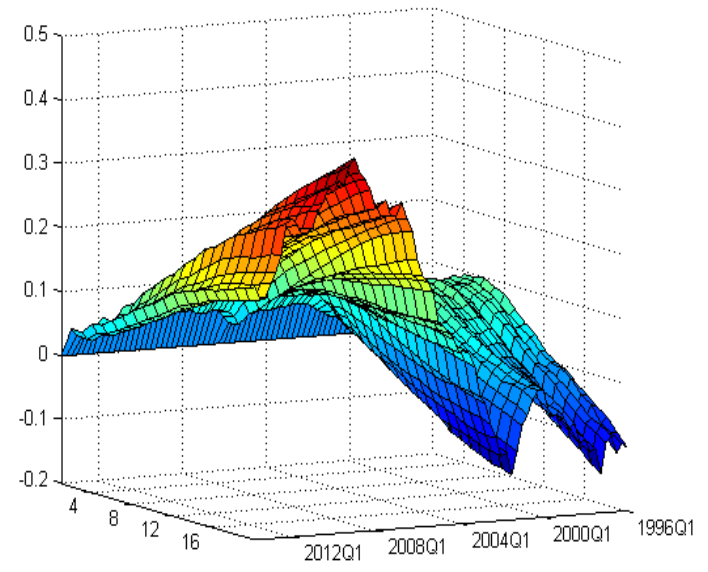

(c) Reserves

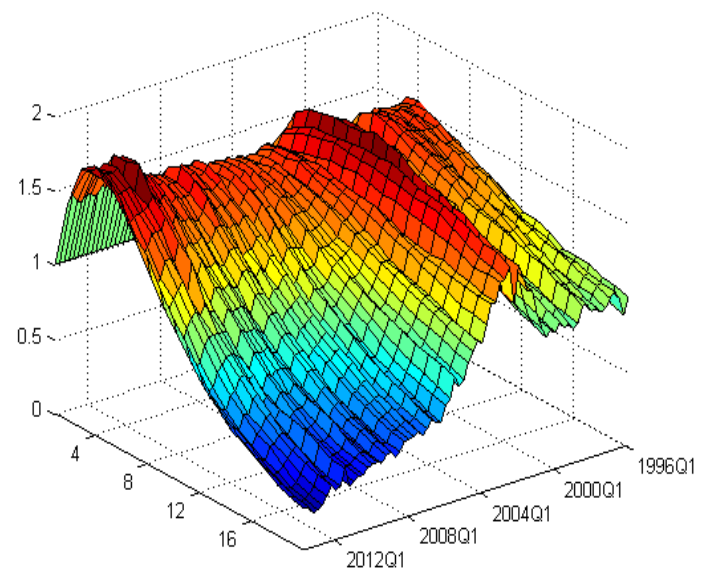

(в) GDP

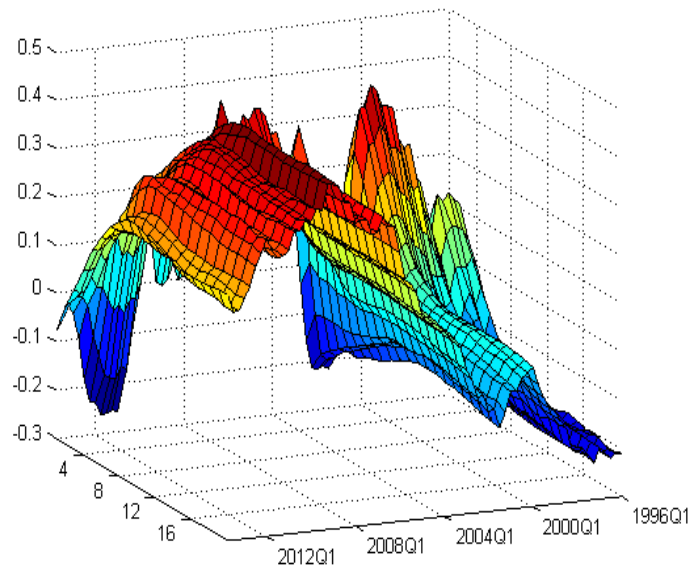

(D) Exchange Rate

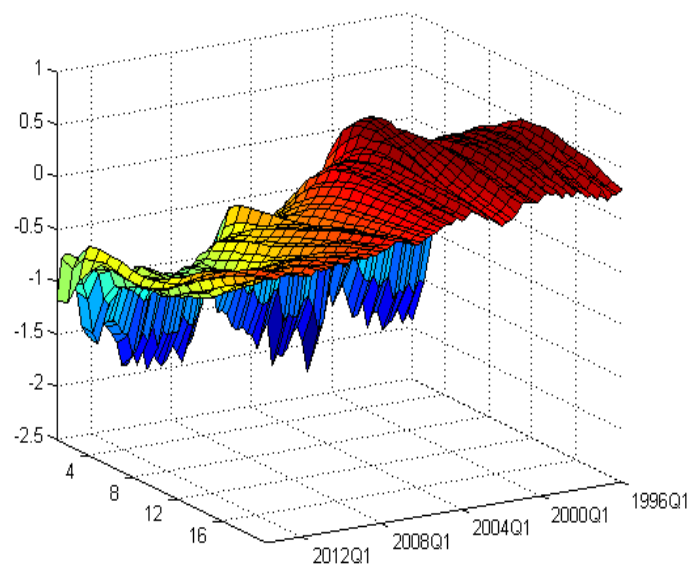

Median impulse responses to a $1 \%$ reserve shock.

Following a QE shock, real GDP initially increases for most of the periods and after 1999 the cumulative effect on output seems to be positive. More specifically, during the ZIRP from 1999 to 2000 the initial response of GDP seems to become stronger. With the end of

\footnotetext{
${ }^{18}$ The BoJ implemented its ZIRP from February 1999 to August 2000 and the first QE program between March 2001 and March 2006. Note that we cannot explicitly control for the monetary policy stances in our estimation method. However, it is very likely that these episodes considerably influenced the transmission mechanism of QE shocks. The estimated changes in our impulse responses seem to occur exactly during these periods.
} 
the ZIRP, in the end of 2000, the initial response of GDP appears to weaken substantially. Since 2002, we see a reversal of this trend: output seems to become initially more responsive from about $-0.2 \%$ in 2002 to $0.2 \%$ in 2003. Between 2004 and 2006, the initial impact of the QE shock has a positive effect on output of about $0.3 \%$ after four quarters. Especially the medium term and long run impact of the QE shock seems to be stronger from 2004 onwards (Figure 4b). The significance of this increase is also reported in Figures 13a and 13b (Appendix E). This positive significant impact on output also seems to hold for the year 2013. Interestingly, we can conclude that QE shocks appear to become visibly more effective as an output stimuli from 2006 onwards (Figures 13a and 13b). This is in contrast to the findings of Kimura et al. (2003) and Kimura and Nakajima (2013). However, also Franta (2011) finds an initial positive and significant impact on output. In line with our results, also Schenkelberg and Watzka (2013) estimate a significant impact on output after about two years.

Note that from about 2008 to 2011, the CPI and GDP responses seem to be larger compared to the other periods. A possible explanation might be that the global financial crisis in 2007/2008 led to a world-wide recession. This recession was to a large extend driven by a decline in aggregate demand. Under such conditions of insufficient aggregate demand as opposed to structural problems of the economy - monetary policy tends to have a large effect. Our results possibly reflect this situation.

Finally, following a QE shock, the real effective exchange rate seems to initially depreciate (Figure 4d). ${ }^{19}$ While the response of the exchange rate to a QE shock is insignificant thereafter, it is only since recently that the depreciation stays significant until about one year following the shock (Figures 13a and 13b). This finding suggests that a QE shock during the 'Abenomics' strategy leads to a somewhat longer depreciation of the Yen. The depreciation may in turn stimulate economic activity at the ZLB.

6.1.1. Comparison of impulse responses at different points in time. For a better illustration of the difference in the impulse responses to a QE shock across time, we also present Figures $5 \mathrm{a}$ and 5b. These allow for a comparison of impulse responses at specific points in time. Figure 5a plots the median impulse responses at 1999Q4, 2003Q3 and 2013Q3. The period around 1999Q4 reflects the environment under the ZIRP period, 2003Q3 under the influence of the first QE program and 2013Q3 under the influence of the current economic policies advocated by Shinzo Abe. The three different time periods for the comparison are chosen arbitrarily within each monetary policy stance. Figure $5 \mathrm{~b}$ plots the impulse responses at

\footnotetext{
${ }^{19}$ A negative value of the real effective exchange rate response reflects a depreciation of the Yen.
} 
$2003 \mathrm{Q} 3$ and 2013Q3 with percentiles. ${ }^{20}$

In terms of prices, as we described above, the positive and significant effect at the long run is visible in Figure 5b below. In contrast, the estimated impact of a monetary base shock in Kimura et al. (2003), Nakajima et al. (2011) and Kimura and Nakajima (2013) does not reveal a strong effect on prices. However, their results could be biased. Kimura et al. (2003) use a time-varying coefficient VAR but with a constant variance covariance matrix. Since the simultaneous relation matrix is time invariant in this case, it could lead to an underestimation of the shocks (see Primiceri (2005) for further details). In contrast, Nakajima et al. (2011) and Kimura and Nakajima (2013) use a fully time-varying VAR which allows for stochastic volatility. However, their results could be driven by the recursive identification system. In accordance with our findings are the results by Franta (2011) and Schenkelberg and Watzka (2013). Both approaches apply sign restrictions and estimate an initial positive and significant impact on prices. Contrary to Franta (2011), our results and Schenkelberg and Watzka (2013) also confirm a permanent significant increase in prices. ${ }^{21}$

Especially for the medium term and long run responses on both prices and GDP, there seems to be a significant difference between 2003Q3 and 2013Q3 (Figure 5a). The confidence bands in Figure 5b reveal a stronger significant impact of a QE shock in 2013Q3 compared to 2003Q3 and 1999Q4. More specifically, the effect on prices seems to be permanent in 2013Q3, whereas the impact in 2003Q3 becomes insignificant after seven quarters. Following a QE shock on GDP in 2013Q3, we estimate a positive and significant impact after seven quarters. Compared to 2013Q3, the effect on GDP in 2003Q3 is completely insignificant. Regarding the exchange rate, a QE shock leads to a somewhat longer depreciation in 2013Q3 than for example during earlier periods. This finding suggests that, in contrast to earlier policy programs by the BoJ, the 'Abenomics' strategy seems to have an impact on the exchange. These results are also supported by our analysis on the posterior probability for the difference in the impulse responses.

We consider the statistical difference in the impulse responses between different time periods by calculating the ratio of the Markov Chain Monte Carlo draws (MCMC) of the responses between two time periods. More specifically, we estimate the posterior probability

\footnotetext{
${ }^{20}$ Figure 14 in Appendix $\mathrm{F}$ presents the average impulse response functions during the three respective monetary policy stances (ZIRP, first QE program, 'Abenomics'). They show that the arbitrarily taken periods (1999Q4, 2003Q3 and 2013Q3) reveal the same findings as the average response during the three monetary policy stances.

${ }^{21}$ See Table 6 to 8 in Appendix B for a more detailed overview of the results obtained in other studies focusing on the monetary policy transmission in Japan.
} 
TABLE 2. Posterior probability for the difference in the impulse responses to a QE shock at different time periods

\begin{tabular}{rccccc}
\hline Horizon & $1 \mathrm{Q}(\%)$ & $4 \mathrm{Q}(\%)$ & $8 \mathrm{Q}(\%)$ & $12 \mathrm{Q}(\%)$ & $16 \mathrm{Q}(\%)$ \\
\hline HICP & & & & & \\
$1999 / 2003$ & 9.5 & 44.6 & 43.7 & 46.7 & 48.6 \\
$1999 / 2013$ & 9.2 & 52.5 & 53.7 & 61.0 & 64.5 \\
$2003 / 2013$ & 9.2 & 52.5 & 53.7 & 61.0 & 64.5 \\
GDP & & & & & \\
$1999 / 2003$ & 36.8 & 40.6 & 46.4 & 49.4 & 50.5 \\
$1999 / 2013$ & 9.4 & 41.7 & 66.1 & 67.4 & 66.6 \\
$2003 / 2013$ & 9.4 & 41.7 & 66.1 & 67.4 & 66.6 \\
Res & & & & & \\
$1999 / 2003$ & 46.0 & 47.1 & 46.4 & 47.6 & 48.0 \\
$1999 / 2013$ & 67.2 & 70.1 & 60.5 & 51.4 & 47.6 \\
$2003 / 2013$ & 67.2 & 70.1 & 60.5 & 51.4 & 47.6 \\
ExR & & & & & \\
$1999 / 2003$ & 34.5 & 37.5 & 39.8 & 40.3 & 40.6 \\
$1999 / 2013$ & 31.2 & 26.1 & 22.0 & 20.0 & 25.9 \\
$2003 / 2013$ & 31.2 & 26.1 & 22.0 & 20.0 & 25.9 \\
\hline
\end{tabular}

Note: Difference in impulse responses at the time periods 1999Q4, 2003Q3 and 2013Q3 for one, four, eight, 12 and 16 quarters ahead.

that the response at one given time period (first considered response) is smaller than at another given time period (second considered response). We consider again the three time periods referred to above and present the posterior differences in the impulse responses to the QE shock in Table 2. Posterior probability values close to $50 \%$ indicate a weak difference between the two periods. Values above (below) $50 \%$ imply that the first response is smaller (bigger) than the second response. Regarding prices, we estimate a strong difference in the initial responses of the three considered time periods as well as in the long run responses in $1999 / 2013$ and $2003 / 2013$, whereas the responses in 1999/2003 are quite similar in the long run. More specifically, values above 60\% for 12 and 16 quarters ahead in 1999/2013 and $2003 / 2013$ indicate a strong difference in the impulse responses. The estimated response in 2013Q3 is larger than in 2003Q3 or 1999Q4. Following a QE shock on GDP, a strong posterior difference is reported for all initial responses of the three considered time periods as well as for the time periods 1999/2013 and 2003/2013 from eight quarters ahead. The difference between 1999 and 2003 seems to be again very small in the long run. The evidence for time 
variation of the exchange rate responses is rather strong between all compared time periods. The responses in 2013 confirm a larger depreciation of the exchange rate than in 2003 and 1999.

Generally, our results suggest that a QE shock during the recent 'Abenomics' period seems to lead to a larger impact on output, prices and the exchange rate than during the ZIRP or the first QE program. A theoretical discussion of our results, based on the Eggertsson (2011) model, follows in section 6.4 below.

\subsection{Impulse Responses to Demand and Supply Shocks.}

The impulse response functions for the demand and supply shocks are given in the Appendix H, Figures 18 and 19. Primarily, we identify these two shocks for (1) evaluating the explanatory power of the QE shock compared to the demand and supply shocks (see section 6.3 for details on the variance decomposition analysis) as well as (2) for ensuring that these business cycle fluctuations do not enter the identified QE shock. In the following, a brief overview of the main effects of the demand and supply shocks is given.

The responses of CPI and GDP is initially restricted to be positive following a demand shock, thus the immediate increase is by construction. More specifically, CPI rises by up to $2 \%$ in 1999Q4 and 2003Q3 and stays significantly above zero for a much longer period than restricted. Generally, this effect also holds for 2013Q3 except that it converges a bit faster back to the zero line. Turning to GDP, it becomes insignificant after the restriction horizon. Reserves and the exchange rate seem to respond insignificantly to a demand shock.

Figure 19 plots the impulse response functions following a supply shock. By comparing the absolute size of the initial CPI and GDP responses to the demand and supply shocks in Figures 18 and 19, the determining sign restrictions can be seen. Following a demand shock, CPI is restricted to respond less strong than GDP and vice versa following a supply shock. The responses of CPI and GDP are as expected significantly negative. The impulse responses remain significant after the restriction horizon. Following a supply shock, we report a non visible effect on reserves and the exchange rate.

Overall, the transmission mechanism of the demand and supply shocks is similar to the findings of Schenkelberg and Watzka (2013). 
Figure 5. Responses at Different Time Periods to a QE Shock

(A) Responses without Percentiles
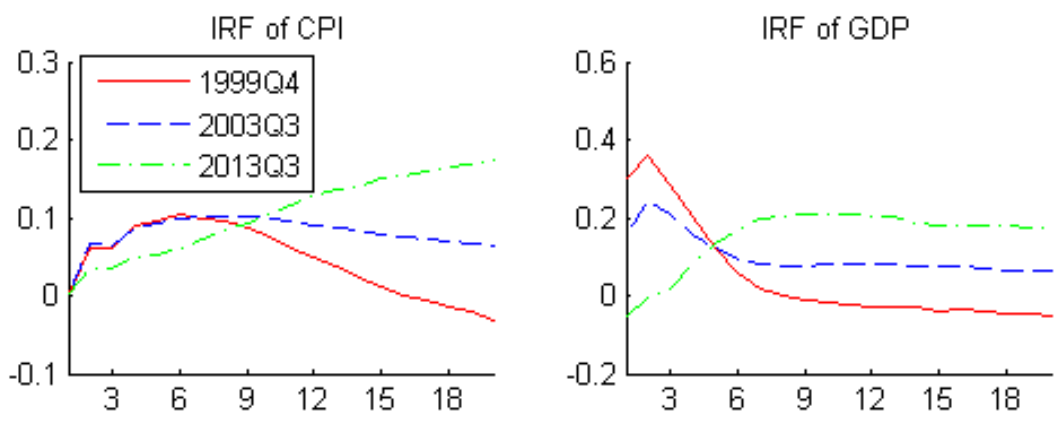

IRF of Res

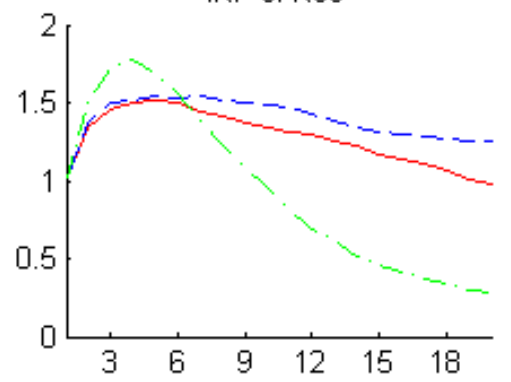

IRF of ExR

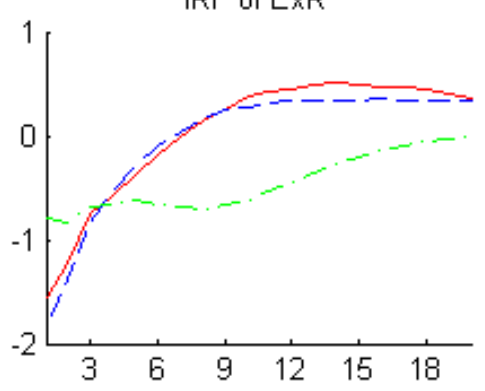

Median impulse responses to a 1\% QE shock at 1999Q4, 2003Q3 and 2013Q3.

(в) Responses with Percentiles

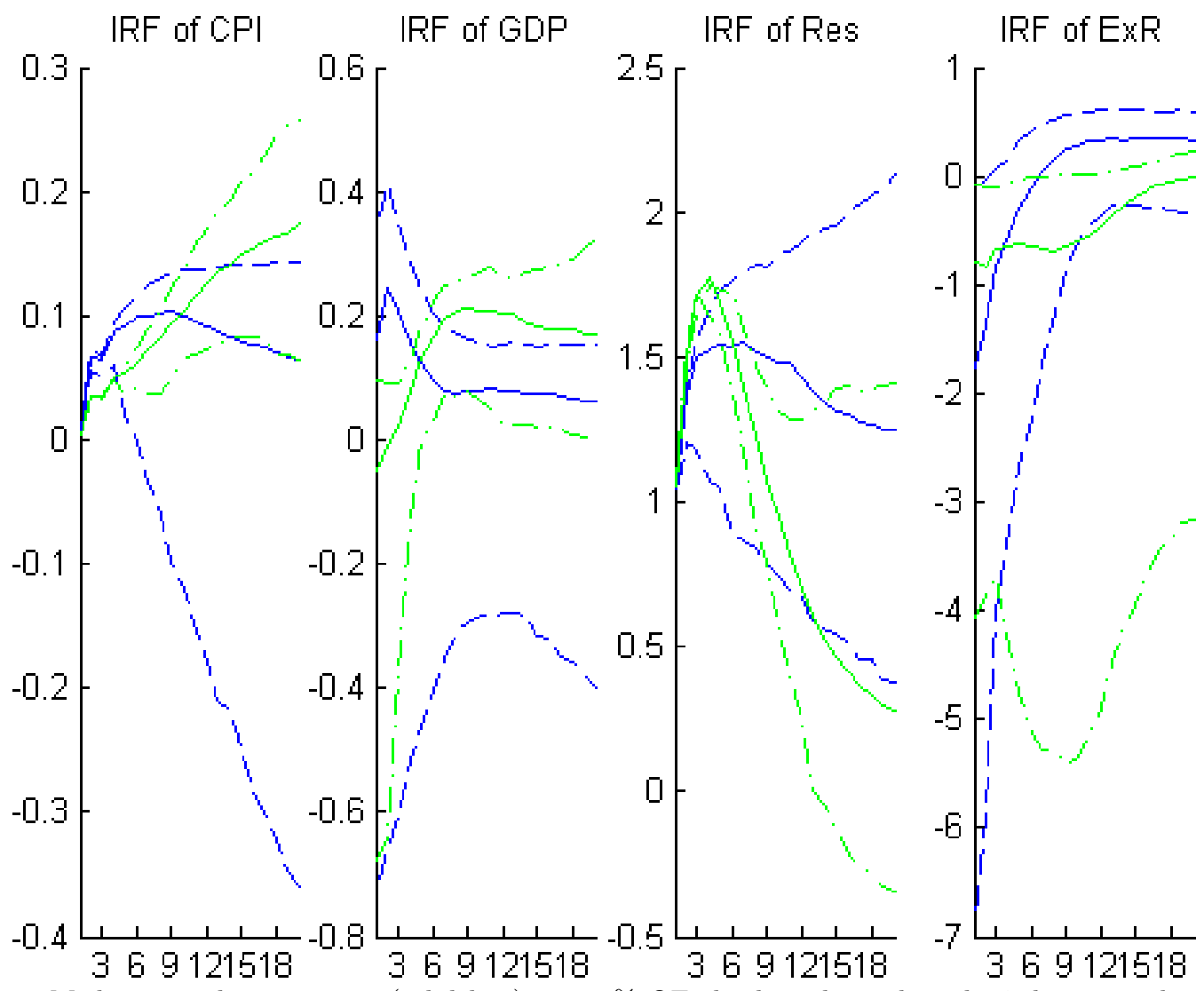

Median impulse responses (solid line) to a $1 \%$ QE shock with 16-th and 84-th percentiles (dashed line) of the posterior distribution at 2003Q3 (blue) and 2013Q3 (green). 


\subsection{Results on the Forecast Error Variance Decomposition.}

The forecast error variance decomposition (FEVD) allows us to analyse the explanatory power of the QE shock relative to the other structural shocks. We use the close-to-median impulse responses in this section for assessing the relative quantitative importance of our three structural shocks. This procedure generates the impulse responses which are closest to the median impulse response functions. By using the close-to-median impulses, we ensure that the variance shares add up to one as well as the orthogonality of the identified shocks. Table 3 summarises the estimated forecast error variance shares of all variables for each of the three identified shocks, for the horizons of 4, 8, 12 and 16 quarters as well as for the time periods 1999Q4, 2003Q3 and 2013Q3. The last column of each time period gives the sum of the variance shares of every endogenous variable over all identified shocks.

To give an example, overall, our three shocks account for up to $98 \%$ of the GDP variability in 1999Q4. ${ }^{22}$ More specifically, the QE shock explains up to $36 \%$ of the GDP variability in 1999Q4 and decreases substantially for 2003Q3. But the explanatory power on GDP in 2013Q3 is considerably larger than during the first QE program in 2003. Also 2013Q3 seems to have an overall larger explanatory power than during the ZIRP in 1999Q4. Regarding the quantitative importance of the QE shock on prices in 2003Q3, it does not appear to play a major role, explaining only $3 \%$ to $7 \%{ }^{23}$ However, especially at longer horizons it seems that the variance shares for prices are higher in 2013Q3 and 1999Q4 compared to 2003Q3, accounting for up to $22 \%$ of the variability in 2013Q3.

The demand shock accounts for a non-negligible part of the variability in GDP with variance shares of up to $47 \%$ in 2003Q3. Similarily for the variance shares of CPI to a supply shock, these range from $48 \%$ to $10 \%$ in 2003Q3. It seems that the explanatory power of the demand shock on CPI and GDP decreases from 2003Q3 to 2013Q3 vice versa for the supply shock. As expected, the QE shock confirms the relatively important role on the variability of reserves; variance shares range from $49 \%$ to $47 \%$ in 2013Q3. In contrast, the other two identified shocks are of minor importance for the reserve variability. These findings are also in line with Schenkelberg and Watzka (2013).

Summing up, in 2013Q3, a QE shock seems to explain a larger variance share of both CPI and GDP. The relative importance of the QE shock in 2013Q3 on prices increases at longer

\footnotetext{
22 The sum would equal one when next to the three identified shocks also the unidentified disturbance, the exchange rate shock, is added.

${ }^{23}$ Generally, relatively low numbers where also estimated by Schenkelberg and Watzka (2013). However, as Peersman and Straub (2006) illustrate, sign restriction approaches often lead to rather small variance shares for some variables.
} 
horizons compared to 2003Q3. Also for GDP, the explanatory power of the QE shock is substantially higher in 2013Q3 than in 2003Q3. These measures possibly mirror the effects of the current 'Abenomics' program and support our previous findings.

TABLE 3. Forecast Error Variance Decomposition

\begin{tabular}{|c|c|c|c|c|c|c|c|c|c|c|c|c|c|}
\hline & & \multicolumn{4}{|c|}{ 1999Q4 } & \multicolumn{4}{|c|}{ 2003Q3 } & \multicolumn{4}{|c|}{ 2013Q3 } \\
\hline Variable & Horizon & $\mathrm{QE}$ & $\mathrm{DE}$ & $\mathrm{SU}$ & Sum & $\mathrm{QE}$ & $\mathrm{DE}$ & $\mathrm{SU}$ & Sum & $\mathrm{QE}$ & $\mathrm{DE}$ & $\mathrm{SU}$ & Sum \\
\hline \multirow[t]{4}{*}{ CPI } & 4 quarters & 8 & 28 & 49 & 85 & 3 & 34 & 48 & 86 & 16 & 16 & 48 & 81 \\
\hline & 8 quarters & 17 & 51 & 25 & 93 & 6 & 45 & 22 & 74 & 16 & 36 & 35 & 86 \\
\hline & 12 quarters & 22 & 58 & 15 & 95 & 7 & 48 & 14 & 69 & 18 & 42 & 29 & 89 \\
\hline & 16 quarters & 25 & 59 & 12 & 96 & 7 & 51 & 10 & 69 & 22 & 41 & 26 & 89 \\
\hline \multirow[t]{4}{*}{ GDP } & 4 quarters & 36 & 46 & 16 & 98 & 2 & 42 & 11 & 55 & 44 & 29 & 12 & 85 \\
\hline & 8 quarters & 34 & 46 & 16 & 96 & 3 & 44 & 10 & 57 & 45 & 22 & 13 & 81 \\
\hline & 12 quarters & 35 & 46 & 15 & 96 & 3 & 46 & 10 & 59 & 47 & 17 & 16 & 79 \\
\hline & 16 quarters & 36 & 45 & 15 & 96 & 5 & 47 & 10 & 61 & 46 & 16 & 17 & 79 \\
\hline \multirow[t]{4}{*}{ Res } & 4 quarters & 90 & 9 & 1 & 100 & 1 & 0 & 1 & 2 & 49 & 15 & 10 & 74 \\
\hline & 8 quarters & 89 & 8 & 2 & 99 & 2 & 1 & 2 & 5 & 47 & 17 & 11 & 76 \\
\hline & 12 quarters & 88 & 7 & 3 & 99 & 5 & 1 & 2 & 8 & 47 & 17 & 12 & 76 \\
\hline & 16 quarters & 87 & 7 & 4 & 98 & 8 & 2 & 2 & 12 & 47 & 17 & 12 & 76 \\
\hline \multirow[t]{4}{*}{ ExR } & 4 quarters & 7 & 14 & 28 & 49 & 71 & 4 & 20 & 95 & 48 & 12 & 17 & 77 \\
\hline & 8 quarters & 11 & 14 & 35 & 59 & 54 & 3 & 26 & 83 & 47 & 12 & 18 & 78 \\
\hline & 12 quarters & 12 & 13 & 36 & 61 & 52 & 3 & 27 & 82 & 47 & 13 & 18 & 77 \\
\hline & 16 quarters & 12 & 13 & 36 & 62 & 50 & 4 & 26 & 80 & 46 & 14 & 18 & 78 \\
\hline
\end{tabular}

Note: Variance shares of the QE shock, the demand and the supply shock. Entries are in percent.

\subsection{Theoretical Discussion of our Results.}

Based on Eggertsson's (2011) model, we briefly discuss potential reasons why the observed effect of a QE shock in 2013 seems to have a significantly stronger impact on prices and GDP than in 2003 or 1999.

In the Eggertsson (2011) model, the economy at the ZLB has an upward sloping aggregate demand curve in inflation. That is, higher inflation expectations increase output because, for a given nominal interest rate, the real interest rate decreases due to a higher inflation rate. This stimulates consumption and thus output (refer to Appendix D for a brief summary of the Eggertsson (2011) model). As Krugman (2000) and Eggertsson (2011) illustrate, for fighting the liquidity trap, monetary policy needs to raise expected inflation through 
a credible commitment to expand the current and future money supply. This in turn will increase the current price level and thus current output. For these real effects to occur, two aspects have to hold: (1) the monetary expansion needs to be perceived by the markets as sustainable and (2) the central bank will not revert to normal practice of stabilising prices as soon as the recession is past. If the central bank cannot credibly promise to be irresponsible, the monetary expansion will be ineffective for fighting the liquidity trap (see subsection D.3 for the effect of a credible monetary policy expansion).

Figure 6 presents the development of Japanese inflation expectations. The development of the expectation of a higher inflation rate within the next six months and for a rise in inflation for one year forward suggest a respective increase during the three monetary policy stances of the BoJ (Figure 6a). As Figure 6b shows, since 2013 expected inflation increased substantially with a pronounced increase in expected inflation between 2 and $5 \%$ as well as more than $5 \%$. This can also be confirmed by looking at the overall development of the expected inflation one year forward (Figure 6b). Moreover, also the medium and long run inflation expectations in Figure 6c reveal a considerable increase since the beginning of the 'Abenomics' strategy. Therefore, inflation expectations appear to be rising on the whole within the last year. Moreover, since the introduction of the 'Abenomics' strategy, also the overall index on consumer prices as well as the core price index already experienced a substantial increase (see Figure 7). For example, the annual growth of CPI increased from $-0.7 \%$ in April 2013 to $1.6 \%$ in December 2013.

Based on Eggertsson (2011) theory, one can argue that the current development in inflation expectations possibly mirrors that markets believe in a sustainable expansionary monetary policy under the 'Abenomics' program and thus to have considerable real effects. ${ }^{24}$ This is also in line with the findings of Hausman and Wieland (2014). More specifically, they describe that, compared to the first QE program, the 'Abenomics' strategy seems to be perceived as non-temporary since the broad money supply experienced a remarkable growth since 2013 compared to the period under the first QE program. This is precisely what one would expect from a more credible monetary policy change. A perceived non-temporary QE program leads to expected lower future real interest rates since expected inflation rises. This in turn increases credit demand and thus induces money creation in the banking sector. Thus, the increase in the broad money supply (see Figure 8 for the differences in monetary base growth between the two programs). Therefore, a credible commitment to future money expansion

\footnotetext{
${ }^{24}$ Figure $6 \mathrm{~b}$ also indicates a rise in consumers' inflation expectations for the period between 2007 and 2009. Based on Eggertsson's (2011) theory, this increase may reflect that markets believe in a credible monetary policy expansion during this period as well leading to a rise in prices and output. Note that following a $\mathrm{QE}$ shock, we estimate a significant impact on prices and GDP after two years since 2006 (compare Figure ??).
} 
may successfully fight the liquidity trap whereas temporary changes in the monetary base may fail to accomplish this. ${ }^{25}$

However, it should be stressed that it is still far too early to conclusively judge on the effectiveness of 'Abenomics'. Thus, our results should be seen as a tentative and preliminary evaluation of the short-term effects of 'Abenomics', much in the line and spirit of Hausman and Wieland (2014).

${ }^{25}$ As Hausman and Wieland (2014) outline, the first QE program was perceived as temporary. Although the broad money aggregate M3 increased after the beginning of the first QE program, the increase was rather small. As for example Krugman (1998) and Eggertsson (2011) (among others) argue, if QE is perceived to have temporary effects, it will only have small or no influence on expected real interest rates and the broad money supply. 
FiguRE 6. Japanese Inflation Expectations

(A) Expected Inflation within the next 6 months and 1 year forward

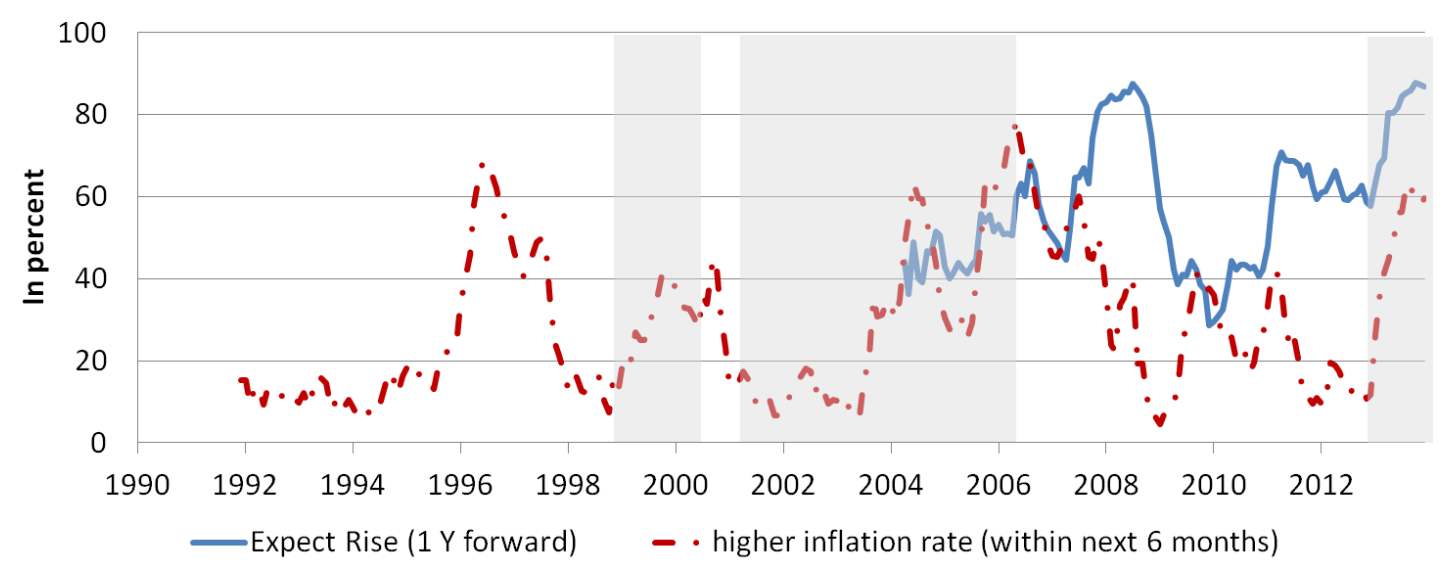

Medium term expectations of a higher inflation rate within the next 6 months (red dashed line), Source: ZEW Financial Market Survey; Expectations for rise in inflation 1 year forward (blue solid line), (incl. 1 person HH.), consumer confidence, not sa, Source: Cabinet Office Japan; Shaded areas: 1999-2000 ZIRP, 2001-2006 1st QE period, 2013-end 'Abenomics' period

(в) Details on Expected Inflation 1 year forward

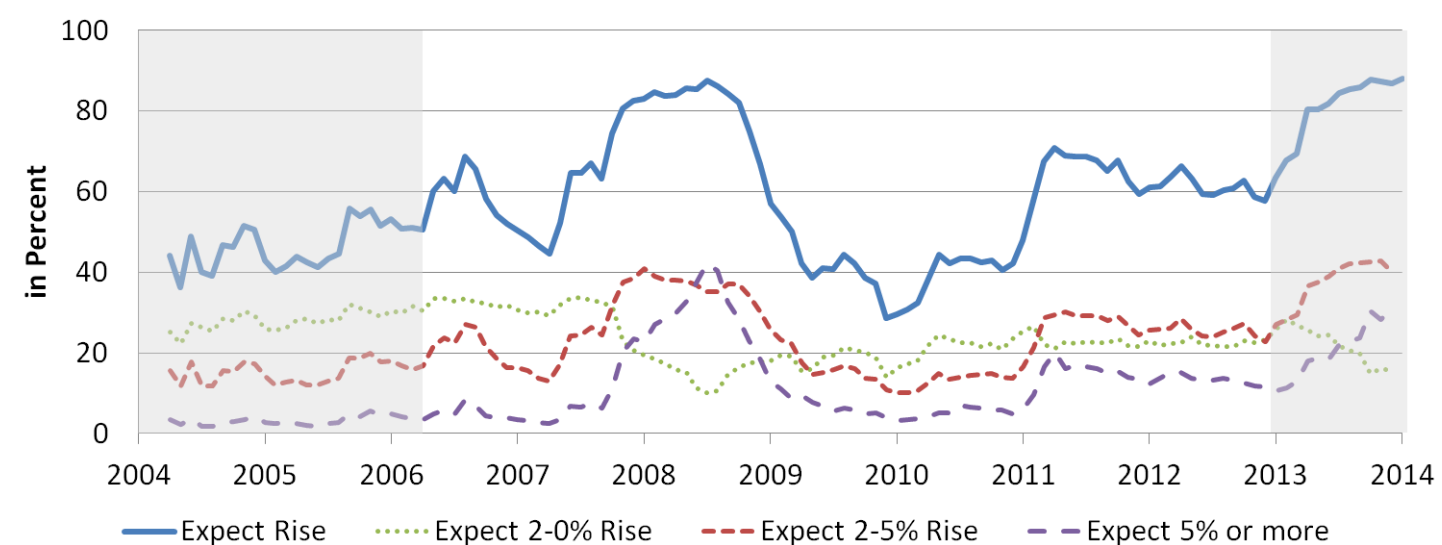

Expectations for rise in inflation 1 year forward, (incl. 1 person HH.), consumer confidence, not sa, Source: Cabinet Office Japan; Shaded areas: 2001-2006 1st QE period, 2013-end 'Abenomics' period

(C) Medium and Long Run Inflation Expectations

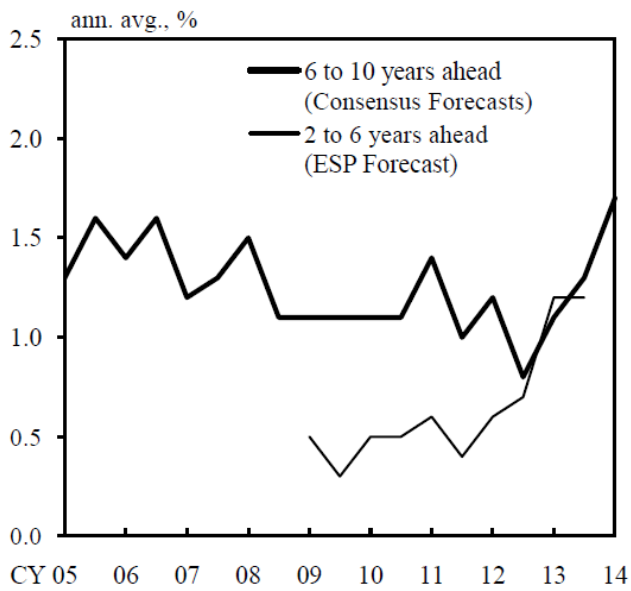

Medium and long run inflation expectations (annual ayerage, \% change) for two to six years ahead as well as six to 10 years ahead. Figures for the ESP Forecast exclude the effects of the consumption tax hikes. Source: BoJ's Monthly Report of Recent Economic and Financial Developments, May 2014, BoJ. 
Figure 7. Annual Inflation Growth

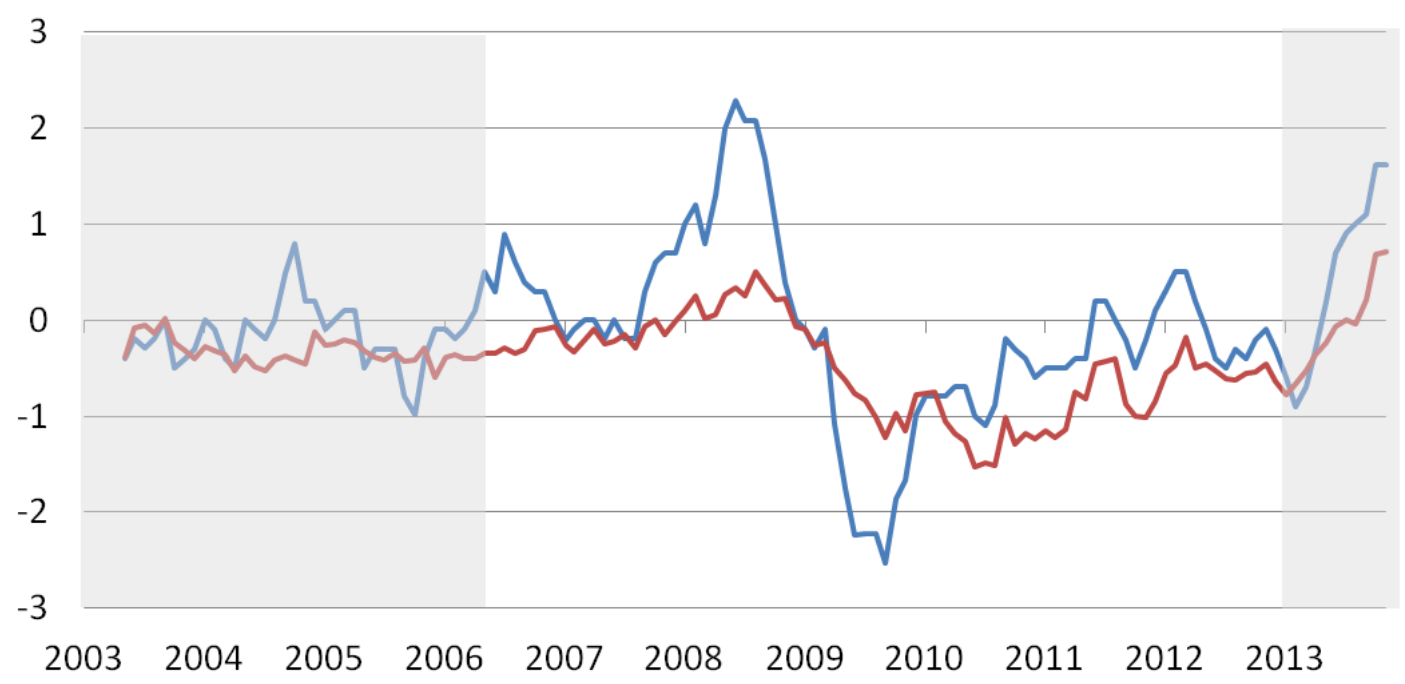

- Consumer Price Index of All Items in Japan

- Core Consumer Price Index: All Items Non-Food and Non-Energy for Japan

Percentage change from a year ago for CPI and core CPI in Japan; Shaded areas: 2001-2006 1st QE period, 2013-end 'Abenomics' period Source: St. Louis Fed

Figure 8. Money Growth during the first QE- and 'Abenomics' program

(B) Broad Money

(A) Monetary Base
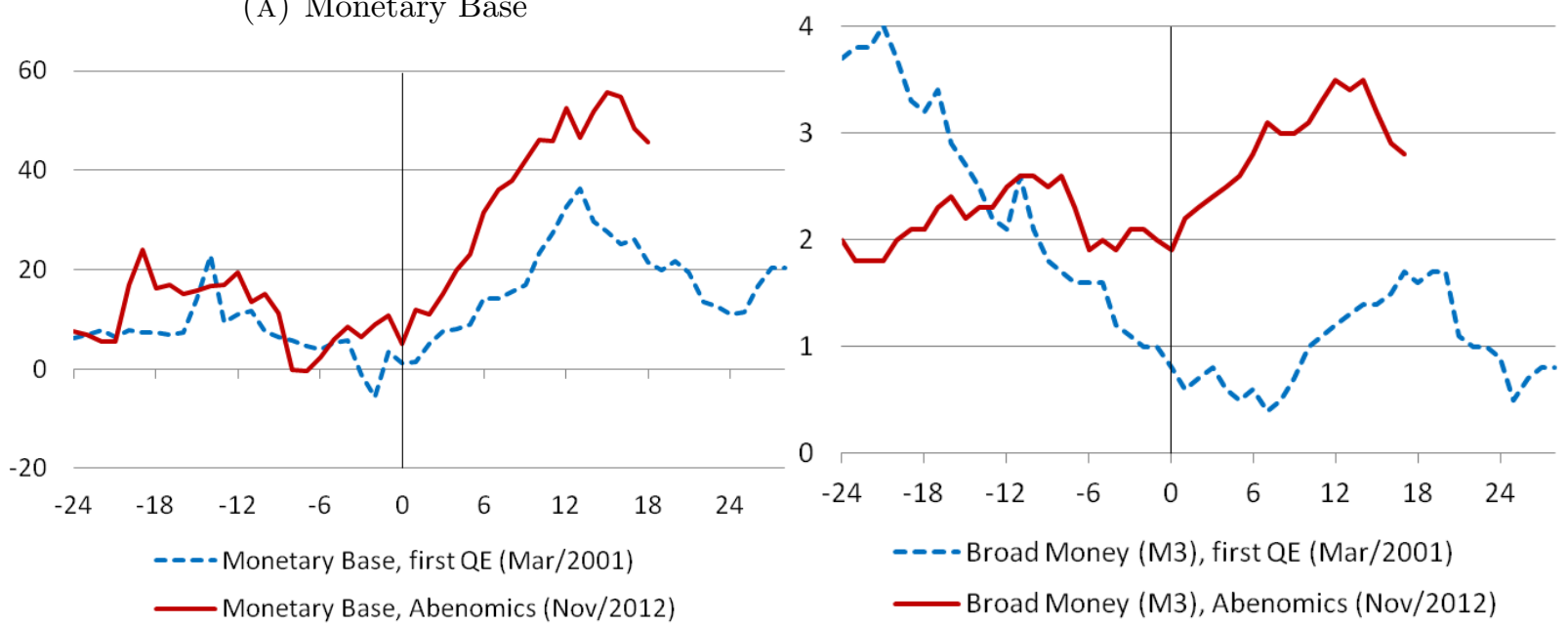

Comparison of money growth between the first QE program and the 'Abenomics' period.

Month 0 denotes March 2001 for the beginning of the first QE program and November 2012 for the 'Abenomics' period. Source: BoJ 


\section{Robustness Checks}

The key focus of this paper is the investigation of the impact of a QE shock over time. Therefore, we concentrate in the following primarily on the QE shock. For reasons of clarity, we present the main figures of our robustness results in Appendix I. More detailed robustness results can be obtained upon request.

7.1. Close-to-median model. The median of the posterior of impulse responses determined by sign restrictions combines responses across different models. As a first robustness check, we investigate whether our results are sensitive to the close-to-median presentation. This procedure gives the impulse response that is the closest to the median impulse response. Figure 20 in Appendix I.1 plots the median as well as the close-to-median impulse responses for the three time periods 1999Q4, 2003Q3 and 2012Q3 to a QE shock. It can be seen that the close-to-median responses are very similar to those based on the median. ${ }^{26}$

7.2. Robustness Checks on Priors. Strictly speaking, one can argue that the ZIRP from 1999 to 2000 is not an official QE policy. For a robustness check, we exclude this period from the estimation sample. Hence, the training sample is extended and based on data from 1980Q1 until 2000Q4. The results confirm those outlined in this paper. Since the TVP-prior could suffer from over-parameterisation, we use as an additional robustness check a hierarchical prior for $B_{0}$. It joins the Minnesota prior with the TVP-prior. The Minnesota prior allows for a shrinkage and thus reduces the risk of over-parameterisation. The results also support the findings presented in this paper. ${ }^{27}$

7.3. Robustness Checks on Identification. We attach special importance to robustness checks on the alteration of the identification of our structural shocks. In the following, we present three variations in the identification scheme.

First, since we use a rather agnostic identification in our benchmark model, we check whether our results to a $\mathrm{QE}$ shock are sensitive to an additional restriction on reserves following a demand shock. We assume that reserves respond negatively $(\leq 0)$ to a demand shock for the first three quarters (Table 4). This additional restriction does not lead to changes in the transmission mechanisms of the QE and supply shocks (compare Figure 21 for the impact of the QE shock). ${ }^{28}$ Following a $\mathrm{QE}$ shock, prices increase significantly in the

\footnotetext{
${ }^{26}$ Results on the close-to-median impulse responses of the the demand and supply shocks resemble the findings based on the median responses as well. Results can be obtained upon request.

27 The robustness results on the priors can be obtained upon request.

${ }^{28}$ Results on the demand and supply shocks can be obtained upon request.
} 
TABLE 4. Sign Restrictions - alternative identification I

\begin{tabular}{ccccc}
\hline \hline & & QE Shock & DE Shock & SP Shock \\
\hline Impact & 0 & & \\
Prices & $K=3$ & $\geq$ & $>$ & $\leq$ \\
\hline GDP & $K=3$ & $?$ & $\geq$ & $<$ \\
\hline Reserves & $K=3$ & $>$ & $\leq$ & $?$ \\
\hline Exchange Rate & $K=3$ & $?$ & $?$ & $?$ \\
\hline Further restriction & $K=3$ & & $\left|\frac{\text { GDP }}{\text { CPI }}\right|>1$ & $\left|\frac{\text { GDP }}{\text { CPI }}\right|<1$ \\
\hline \hline
\end{tabular}

Note: ? denotes no restriction, $>$ defines a positive effect of the respective shock on the variable, vice versa for $<. K=3$ indicates that the restriction horizon is three quarters. $\mid$ GDP/CPI denotes the absolute value of the ratio between the GDP response and the CPI response.

long and short run in 2013 whereas the impact in 2003 stays significant only until about two years after the shock. GDP starts to increase significantly after about two years. In contrast, the GDP response in 2003 is insignificant. Also the impact of the demand shock confirms our results presented, except for reserves. More specifically, we observe an insignificant response of reserves in our benchmark specification, while, the additionally imposed restriction in this identification scheme leads by definition to a slight significant decrease in reserves following a demand shock. The effect on the other endogenous variables is unaltered. In the light of this finding, we can assure to credibly distinguish the QE shock from the demand shock in our benchmark model. ${ }^{29}$

Second, again starting from our benchmark model we now assume a zero restriction on impact on GDP following the QE shock (see Table 5). Thus, CPI and GDP are both restricted to have a lagged response to a QE shock. Figure 22 in Appendix I.3 shows that our results for the time periods 1999Q4 and 2003Q3 are basically insensitive to this change. For 2013Q3 we observe a slightly more visible effect on CPI and GDP. The responses seem to be stronger and longer lasting than under the benchmark identification scheme. Using a zero restriction on impact seems natural. However, against the background of quarterly data and the analysis of unconventional monetary policy shocks, imposing a more conservative identification scheme

\footnotetext{
${ }^{29}$ With the additional restriction on reserves in this section, we specify a stronger assumption on the differences between the transmission of the $\mathrm{QE}$ shock and the demand shock. This ensures to credibly distinguish between the QE and the demand shock. As this sensitivity check leaves the estimated effect on output, prices and the exchange rate compared to the benchmark model unchanged, it assures that we credibly distinguish the QE shock from the demand shock in our benchmark model.
} 
with a zero restriction on GDP might be too restrictive. Therefore, we recommend to stay agnostic on the initial impact on GDP following a QE shock.

TABLE 5. Sign Restrictions - alternative identification II

\begin{tabular}{ccccc}
\hline \hline & & QE Shock & DE Shock & SP Shock \\
\hline & Impact & 0 & & \\
Prices & $K=3$ & $\geq$ & $>$ & $\leq$ \\
GDP & $K=3$ & $?$ & $\geq$ & $<$ \\
\hline Reserves & $K=3$ & $>$ & $?$ & $?$ \\
\hline Exchange Rate & $K=3$ & $?$ & $?$ & $?$ \\
\hline Further restriction & $K=3$ & & $\left|\frac{\text { GDP }}{\text { CPI }}\right|>1$ & $\left|\frac{\text { GDP }}{\text { CPI }}\right|<1$ \\
\hline \hline
\end{tabular}

Note: ? denotes no restriction, $>$ defines a positive effect of the respective shock on the variable, vice versa for $<. K=3$ indicates that the restriction horizon is three quarters. $|\mathrm{GDP} / \mathrm{CPI}|$ denotes the absolute value of the ratio between the GDP response and the CPI response.

Third, we employ a more traditional identification scheme and use a recursive identification based on monthly data with six lags. The ordering of our variables follows: $y_{t}=C P I_{t}$, Output $_{t}, \operatorname{Res}_{t}, E x R_{t}$, where output refers to industrial production in the monthly version. These restrictions are implied by more traditional VAR studies such as Kimura et al. (2003) and Nakajima et al. (2011). Figure 23 in Appendix I.4 summarises the respective results. They basically confirm those presented in this paper. The impact of the QE shock leads to a more pronounced increase in prices and output for 2013Q3 compared to the responses in 2003Q3 or 1999Q4. Note that the significance of the price response vanishes for 2003Q3 and it remains only slightly significant between about one until two years in 2013Q3. As before, the output response in 2003Q3 stays insignificant and we observe a significant response in 2013Q3 between one and three years after the shock.

7.4. Robustness Checks on Data. Since many studies on the Japanese economy use output gap as an output measure, we reestimate our analysis and substitute GDP with output gap. ${ }^{30}$ The results confirm those presented above. However, we abstain from using it due to its forward looking nature. Results can be obtained upon request.

\footnotetext{
${ }^{30}$ Output gap of the total economy, seasonally adjusted, quarterly series, source: OECD.
} 


\section{Conclusion}

This paper uses a new kind of sign restriction in a TVP-VAR framework. It allows to analyse the impact of QE shocks over time when the economy is close to or at the Zero Lower Bound (ZLB). Our findings show that the reaction of macroeconomic variables in Japan to a QE shock has, indeed, varied over time. Especially GDP and prices reveal considerable time-varying effects across our sample from 1996 until 2013. Overall, our results suggest that the impact on GDP and prices, following a QE shock (1\% increase in reserves), has become stronger and longer lasting over time.

More specifically, a comparison of the three considered time periods (1999Q4, 2003Q3 and 2013Q3) ${ }^{31}$ shows that GDP responds significantly in 2013Q3 to a QE shock whereas in 2003Q3 and 1999Q4 the response is insignificant. Turning to prices, we generally report a visible response following a QE shock. Note that compared to 1999Q4 and 2003Q3, the price response in 2013Q3 stays permanently significant.

Regarding the relative explanatory power of a QE shock, we observe that a $\mathrm{QE}$ shock seems to explain a larger variance share of prices in 2013Q3 compared to 1999Q4 and 2003Q3. Also for GDP, the explanatory power of the QE shock is considerably higher in 2013Q3 than in 2003Q3. The generally more pronounced effects in 2013 possibly mirror the influence of the current 'Abenomics' program. However, it should be noted that it may still be too early to make a definite evaluation on the effectiveness of 'Abenomics'. Thus, our findings should be taken as a preliminary assessment on the short-term effects of 'Abenomics'.

We would like to stress the robustness checks conducted for testing the consistency of our results. The use of the TVP-VAR with stochastic volatility is also supported by a marginal likelihood estimation based on the modified harmonic mean estimator that compares the TVP-VAR with a constant BVAR. Moreover, a sophisticated model selection algorithm is used to ensure the correct specification of the prior beliefs about the amount of time variation. Further, we implement several checks on the prior specifications, identifications and data. Additionally, we reestimate the impulse response functions based on the close-tomedian responses. Our results presented in this paper seem to be largely insensitive to these alterations.

\footnotetext{
${ }^{31}$ The three time periods are chosen arbitrarily within each monetary policy stance of the BoJ. They refer to the ZIRP, the first QE program and the 'Abenomics' strategy respectively.
} 


\section{Appendix A. Data sources}

This paper uses quarterly data on Japan and covers a time horizon between 1980:1 and 2013:4. We estimate the model in detrended levels. Like Sims et al. (1990) state, this accounts for possible discrepancy which may arise in case of incorrectly assumed cointegration restrictions. Also, if there are unit roots in the data, it will not influence the likelihood function, since nonstationarity is of no concern in a Bayesian framework. In the following, the used time series are described:

Gross domestic product (GDP): Log of real gross domestic product (2010=100), seasonally adjusted, quarterly series. Source: Datastream.

Core Consumer prices (CPI): Log of core consumer price index, all items less food (also less alcoholic beverages) and energy $(2010=100)$, monthly index converted to a quarterly series (averaging over three respective months), not seasonally adjusted. Source: Datastream.

Reserves (Res): Log of monetary base (reserve requirement rate change unadj.), in hundreds of millions Japanese Yen, average outstanding amounts, current prices, seasonally adjusted. Monthly series converted to a quarterly series (averaging over three respective months). Source: Bank of Japan.

Exchange rate (ExR): Log of Japanese Yen real effective exchange rate index $(2010=100)$, trade weighted exchange rate, CPI deflated, not seasonally adjusted. Monthly index converted to a quarterly series (averaging over three respective months). Source: Bank of Japan. 
Figure 9. Quarterly Data, Japan

(A) GDP in levels

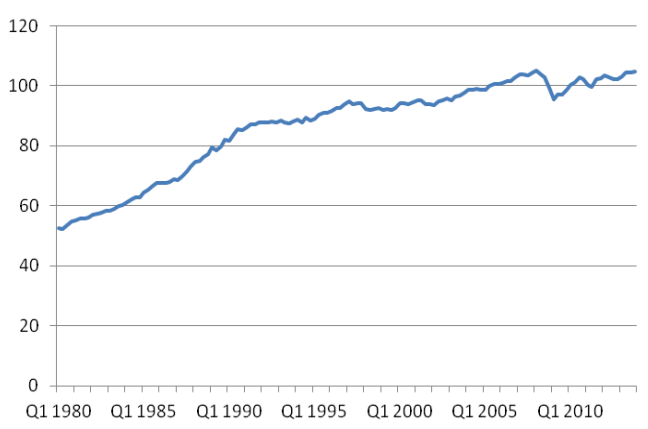

(c) Core CPI in levels

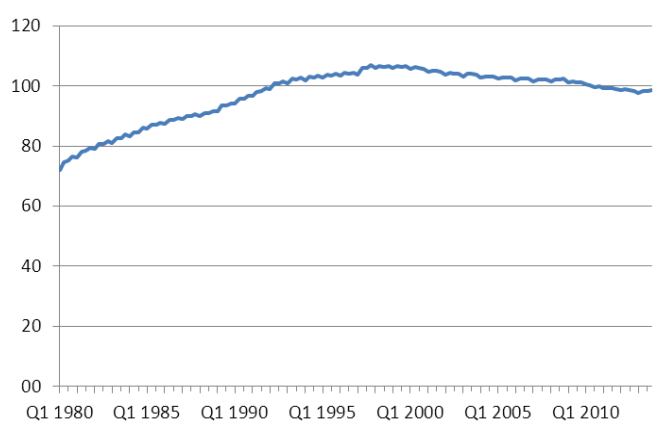

(E) Res in levels

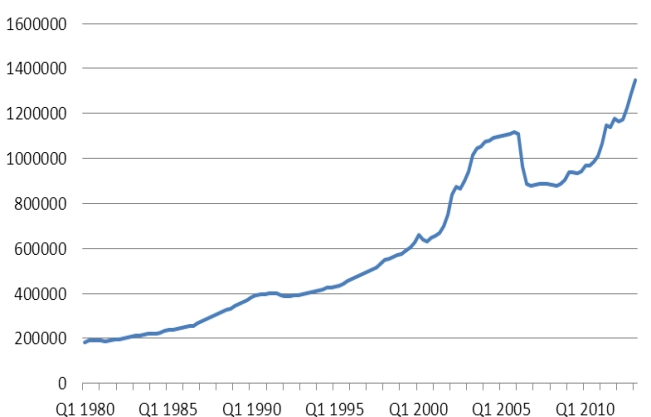

(B) GDP, yearly growth rate

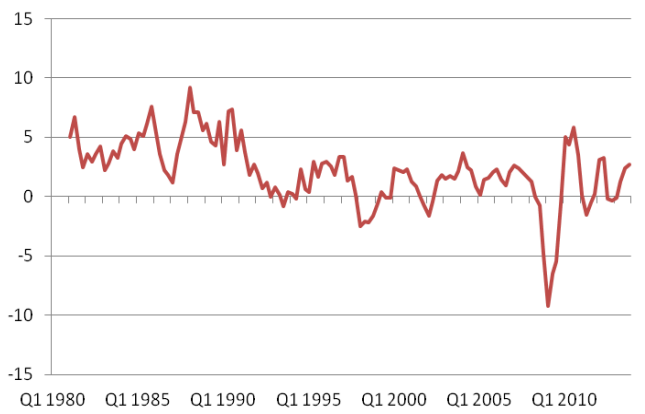

(D) Core CPI, annual rate of change

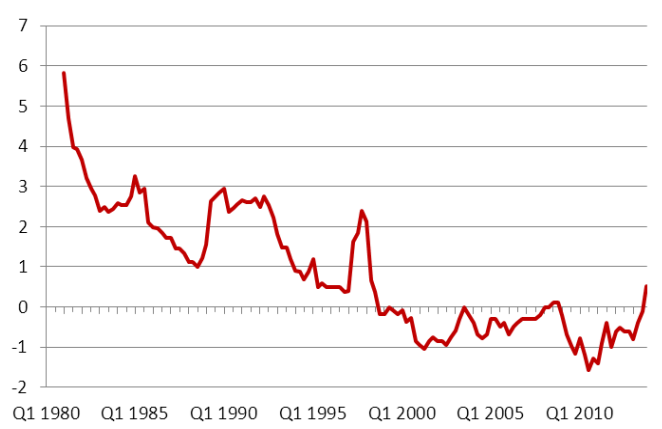

(F) ExR in levels

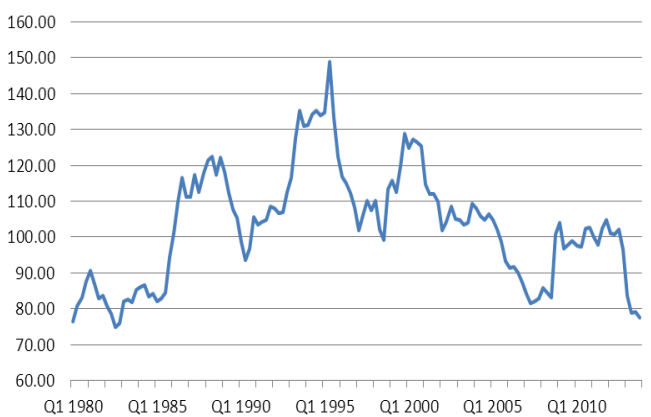


Appendix B. Literature Overview of VAR-Studies on JAPAN

TABLE 6. VAR-Literature Overview of Monetary Transmission in Japan

\begin{tabular}{|c|c|c|c|c|}
\hline Author(s) & Methodology & Identification & Data & Results \\
\hline $\begin{array}{l}\text { Schenkelberg } \\
\text { and Watzka } \\
(2013)\end{array}$ & Bayesian VAR & $\begin{array}{l}\text { Sign restrictions on } \\
\text { QE shock }\end{array}$ & $\begin{array}{l}1995 M 3- \\
2010 M 9 ; \quad \text { CPI, } \\
\text { Industrial } \\
\text { production } \\
\text { (IP), reserves, } \\
\text { government } \\
\text { bond (10 years), } \\
\text { exchange rate }\end{array}$ & $\begin{array}{l}\text { - Benchmark VAR, QE shock } \\
\text { (positive): CPI positive significant; } \\
\text { IP during first } 12 \text { month negative } \\
\text { insignificant thereafter positive and } \\
\text { slightly significant; exchange rate } \\
\text { initially depreciates, insignificant } \\
\text { - Pre } 1995 \text { period VAR with call rate, } \\
\text { MP shock (negative): CPI and IP } \\
\text { increase significantly; exchange rate } \\
\text { initially appreciates significantly, } \\
\text { then depreciates significantly } \\
\text { - also estimate price and output } \\
\text { shock at the ZLB }\end{array}$ \\
\hline $\begin{array}{l}\text { Franta } \\
(2011)\end{array}$ & $\begin{array}{l}\text { TVP-VAR } \\
\text { with stochastic } \\
\text { volatility }\end{array}$ & $\begin{array}{l}\text { Sign restrictions on } \\
\text { monetary policy } \\
\text { shock (specific to } \\
\text { monetary policy } \\
\text { regime) }\end{array}$ & $\begin{array}{l}\text { 1971Q1-2010Q3; } \\
\text { Industrial } \\
\text { production } \\
\text { (IP), CPI, call } \\
\text { rate or current } \\
\text { outstanding } \\
\text { amounts, } \\
\text { monetary base }\end{array}$ & $\begin{array}{l}\text { - Comparision of pre ZIRP with } \\
\text { QE: IP positive and significant } \\
\text { for two quarters, similar response } \\
\text { for both periods; CPI initially } \\
\text { positive for QE, pre ZIRP no effect } \\
\text { - Comparision of ZIRP and } \\
\text { QE: no difference between two } \\
\text { periods for IP and CPI responses } \\
\text { - Comparision Financial Crisis: no } \\
\text { difference between crisis periods for IP } \\
\text { and CPI responses }\end{array}$ \\
\hline $\begin{array}{l}\text { Kimura et al. } \\
(2003)\end{array}$ & $\begin{array}{l}\text { VAR and TV- } \\
\text { VAR with } \\
\text { time-varying } \\
\text { coefficients } \\
\text { but constant } \\
\text { variance matrix }\end{array}$ & $\begin{array}{l}\text { Recursive } \\
\text { identification }\end{array}$ & $\begin{array}{l}\text { 1980Q }-2002 Q 1 ; \\
\text { CPI, } \quad \text { GDP } \\
\text { gap, call rate, } \\
\text { monetary base }\end{array}$ & $\begin{array}{l}\text { - VAR, monetary base shock } \\
\text { (positive): CPI and GDP } \\
\text { gap increase but insignificant } \\
\text { - VAR, interest rate shock (positive): } \\
\text { CPI increase significantly; GDP } \\
\text { gap decreases insignificantly } \\
\text { - TV-VAR, monetary base shock } \\
\text { (positive): CPI increases stronger in } \\
\text { 1985Q2; in } 2002 \text { no impact visible; } \\
\text { GDP gap no impact visible for } 1985 \\
\text { and } 2002\end{array}$ \\
\hline
\end{tabular}


TABLE 7. VAR-Literature Overview of Monetary Transmission in Japan

\begin{tabular}{|c|c|c|c|c|}
\hline Author(s) & Methodology & Identification & Data & Results \\
\hline $\begin{array}{l}\text { Kimura and } \\
\text { Nakajima } \\
(2013)\end{array}$ & $\begin{array}{l}\text { Latent } \\
\text { threshold model } \\
\text { by Nakajima } \\
\text { and West (2013) } \\
\text { combined with } \\
\text { a TVP-VAR } \\
\text { with stochastic } \\
\text { volatility }\end{array}$ & $\begin{array}{l}\text { Recursive } \\
\text { identification } \\
\text { switching with } \\
\text { a time-varying } \\
\text { overidentifcation } \\
\text { for the interest } \\
\text { rate ZLB }\end{array}$ & $\begin{array}{l}\text { 1981Q2-2012Q3; } \\
\text { CPI, GDP } \\
\text { gap, call rate, } \\
\text { outstanding } \\
\text { balance of } \\
\text { current accounts, } \\
\text { goverment bond } \\
\text { (10 years) }\end{array}$ & $\begin{array}{l}\text { - Call rate shock (negative) } \\
\text { if not QE period: CPI } \\
\text { until mid 90s positive } \\
\text { (slightly significant at } \\
\text { some periods), thereafter } \\
\text { insignificant; GDP until end } \\
\text { of 90s positive significant, } \\
\text { thereafter insignificant } \\
\text { - Bank reserves shock } \\
\text { (positive) during QE } \\
\text { period: CPI and GDP } \\
\text { positive but insignificant } \\
\text { - Long term IR shock } \\
\text { (negative) during QE and } \\
\text { not QE period: CPI and } \\
\text { GDP positive, significant } \\
\text { until beginning/mid 90s } \\
\text { - also estimate price and } \\
\text { output shock }\end{array}$ \\
\hline $\begin{array}{l}\text { Hayashi } \\
\text { and Koeda } \\
(2014)\end{array}$ & $\begin{array}{l}\text { Regime } \\
\text { switching SVAR }\end{array}$ & $\begin{array}{l}\text { Recursive } \\
\text { identification }\end{array}$ & $\begin{array}{l}1988-2012 \\
\text { (monthly); CPI, } \\
\text { GDP gap, call } \\
\text { rate, excess } \\
\text { reserves }\end{array}$ & $\begin{array}{l}\text { QE shock (positive), base } \\
\text { period Feb 2004: inflation } \\
\text { increases significantly } \\
\text { between 8-12 months after } \\
\text { shock; GDP increases } \\
\text { significantly and lasts for } \\
\text { two years }\end{array}$ \\
\hline $\begin{array}{l}\text { Nakajima } \\
\text { et al. (2011) }\end{array}$ & $\begin{array}{l}\text { TVP-VAR } \\
\text { with stochas- } \\
\text { tic volatility } \\
\text { and short rate } \\
\text { as censored } \\
\text { variable }\end{array}$ & $\begin{array}{l}\text { Recursive } \\
\text { identification }\end{array}$ & $\begin{array}{l}\text { 1981Q1-2008Q3; } \\
\text { CPI, Industrial } \\
\text { production } \\
\text { (IP), call rate, } \\
\text { monetary } \\
\text { base (average } \\
\text { outstanding } \\
\text { amounts) }\end{array}$ & $\begin{array}{l}\text { Call rate shock (positive): } \\
\text { CPI decreases until end of } \\
80 \mathrm{~s} \text {, gets significant after } 1 \\
\text { year, increases in beginning } \\
\text { of } 90 \mathrm{~s} \text { significantly (price } \\
\text { puzzle), decreases again } \\
\text { in the beginning of 00s } \\
\text { insignificantly; IP decreases, } \\
\text { for } 2002 \text { insignificant, before } \\
\text { significant after } 5 \text { months }\end{array}$ \\
\hline
\end{tabular}


TABLE 8. VAR-Literature Overview of Monetary Transmission in Japan

\begin{tabular}{|c|c|c|c|c|}
\hline Author(s) & Methodology & Identification & Data & Results \\
\hline $\begin{array}{l}\text { Nakajima } \\
\text { and Ginkō } \\
(2011)\end{array}$ & $\begin{array}{l}\text { TVP-VAR } \\
\text { with stochas- } \\
\text { tic volatility } \\
\text { and censored } \\
\text { interest rate } \\
\text { with latent } \\
\text { variable }\end{array}$ & $\begin{array}{l}\text { Recursive } \\
\text { identifcation, } 4 \\
\text { lags }\end{array}$ & $\begin{array}{l}\text { 1977Q1-2010Q2; } \\
\text { CPI, GDP } \\
\text { gap, call rate, } \\
\text { government bond } \\
\text { (5 years) }\end{array}$ & $\begin{array}{l}\text { - Call rate shock (positive): } \\
\text { CPI (price puzzle at } 1 \\
\text { year horizon) negative } \\
\text { until 2000, thereafter } \\
\text { no impact; GDP gap } \\
\text { strongly negative until } 1995 \\
\text { - Bond shock (positive): } \\
\text { CPI initially since } 1995 \text { no } \\
\text { impact, at } 1 \text { year horizon } \\
\text { negative impact across } \\
\text { sample; GDP gap since } \\
\text { 1995 no impact, at } 1 \text { year } \\
\text { horizone slightly negative } \\
\text { and after } 2 \text { years positive } \\
\text { - also estimate price and } \\
\text { output shock }\end{array}$ \\
\hline $\begin{array}{l}\text { Nakajima } \\
(2011)\end{array}$ & $\begin{array}{l}\text { TVP-VAR } \\
\text { with stochastic } \\
\text { volatlity }\end{array}$ & $\begin{array}{l}\text { Recursive } \\
\text { identification }\end{array}$ & $\begin{array}{l}\text { 1977Q1-2007Q4; } \\
\text { CPI, GDP gap, } \\
\text { call rate or } \\
\text { government bond } \\
\text { (5 years) }\end{array}$ & $\begin{array}{l}\text { - MP shock with bond } \\
\text { (positive): CPI until mid } \\
\text { 90s initially positive (price } \\
\text { puzzle) then negative, } \\
\text { since mid 90s in medium- } \\
\text { term/long run no impact; } \\
\text { GDP gap until mid } \\
\text { 90s strongly negative, } \\
\text { thereafter no impact } \\
\text { - MP shock with call rate } \\
\text { (positive): CPI, price puzzle } \\
\text { less evident, decline until } \\
\text { mid 90s, thereafter slightly } \\
\text { positive; GDP gap initially } \\
\text { negative across whole } \\
\text { sample, medium term/long } \\
\text { run negative until } 2000 \\
\text { - also estimate price and } \\
\text { output shock }\end{array}$ \\
\hline
\end{tabular}


Appendix C. Posterior Probability Estimates for $k_{Q}, k_{W}$ and $k_{S}$

TABle 9. Posterior Probability Estimates for $k_{Q}, k_{W}$ and $k_{S}$ based on the RJMCMC Method

\begin{tabular}{rcccr}
\hline \hline Model & $k_{Q}$ & $k_{W}$ & $k_{S}$ & Posterior probability \\
\hline 1 & 0.0100 & 0.0100 & 0.0010 & 0 \\
2 & 0.0500 & 0.0100 & 0.0010 & 0 \\
3 & 0.1000 & 0.0100 & 0.0010 & 0 \\
4 & 0.0100 & 0.0250 & 0.0010 & 0 \\
5 & 0.0100 & 0.0250 & 0.0100 & 0.02 \\
6 & 0.0100 & 0.1000 & 0.0010 & 0 \\
$\mathbf{7}$ & $\mathbf{0 . 0 1 0 0}$ & $\mathbf{0 . 1 0 0 0}$ & $\mathbf{0 . 0 1 0 0}$ & $\mathbf{0 . 9 9 4}$ \\
8 & 0.0100 & 0.0100 & 0.0100 & 0 \\
9 & 0.0500 & 0.0250 & 0.0010 & 0.0007 \\
10 & 0.0500 & 0.0250 & 0.0100 & 0.0003 \\
11 & 0.0500 & 0.0100 & 0.0100 & 0 \\
12 & 0.0500 & 0.1000 & 0.0010 & 0.0027 \\
13 & 0.0500 & 0.1000 & 0.0100 & 0 \\
14 & 0.1000 & 0.0250 & 0.0010 & 0 \\
15 & 0.1000 & 0.1000 & 0.0010 & 0 \\
16 & 0.1000 & 0.1000 & 0.0100 & 0 \\
17 & 0.1000 & 0.0250 & 0.0100 & 0.0003 \\
18 & 0.1000 & 0.0100 & 0.0100 & 0 \\
\hline \hline
\end{tabular}

Note: Posterior probability estimates are based on the reversible jump Markov chain Monte Carlo method for the set of 18 models. These are constructed from all possible combinations of $k_{Q}=\{0.01 ; 0.05 ; 0.1\}, k_{W}=\{0.001 ; 0.01\}$ and $k_{S}=\{0.01 ; 0.025 ; 0.1\}$. 


\section{Appendix D. Eggertsson (2011) Model}

In the following, we briefly summarise the New Keynesian model of Eggertsson (2011). ${ }^{32}$

A negative preference shock moves the economy to the ZLB and induces a fall in output. After this shock, the economy reverts back to its steady state with probability $1-\mu$. It stays at the ZLB with probability $\mu$. Monetary policy is assumed to follow a Taylor rule and is approximated by:

$$
i_{t}=\max \left\{0, r_{t}^{e}+\phi_{\pi} \pi_{t}+\phi_{Y} \hat{Y}_{t}\right\}
$$

with $r_{t}^{e}$ denoting the exogenous shock, $\pi_{t}$ the inflation rate and $\hat{Y}_{t}$ the output gap. $\phi_{\pi}$ and $\phi_{Y}$ are the respective Taylor rule coefficients. The 0 in equation D.1 accounts for the ZLB state. Monetary policy can then be written to have the following form:

$$
\begin{gathered}
i_{t}=r_{H}^{e} \text { for } t \geq T^{e} \\
i_{t}=0 \text { for } 0<t<T^{e},
\end{gathered}
$$

where $r_{H}^{e}$ refers to the negative preference shock in the non-recession state and $T^{e}$ depicts some stochastic date when the economy returns back to its steady state. In the case of the binding ZLB $\left(t<T^{e}\right)$, the $\mathrm{AD}$ and $\mathrm{AS}$ equations ${ }^{33}$ are given by:

$$
\begin{gathered}
A D \quad \hat{Y}_{L}=\mu \hat{Y}_{L}+\sigma \mu \pi_{L}+\sigma r_{L}^{e} \\
A S \quad \pi_{L}=\kappa \hat{Y}_{L}+\beta \mu \pi_{L},
\end{gathered}
$$

where $\mathrm{L}$ denotes the recession state, $r_{L}^{e}$ the negative preference shock in the recession state and $\sigma, \kappa>0$ and $0<\beta<1$.

Note that for the case of a multiperiod recession, where the ZLB is binding for more than one period $(\mu>0)$, both the aggregate demand and supply curve are upward sloping in inflation. The peculiar case of an upward sloping demand curve occurs since, for a given nominal interest rate, the real interest rate increases due to a lower inflation rate today which implies lower expected inflation $\left(\mu \pi_{L}<0\right) .{ }^{34}$ Higher real interest rates are contractionary and induce aggregate demand to fall because current consumption is relatively more expensive than future consumption. Thus, households increase their current savings for future consumption. This in turn reduces current output. Therefore, inflation and output are both upward sloping (compare Figure 10).

\footnotetext{
${ }^{32}$ The notation follows Schenkelberg and Watzka (2013).

${ }^{33} \mathrm{AD}$ and $\mathrm{AS}$ are respectively referring to aggregate demand and aggregate supply

${ }^{34} \mathrm{At}$ the ZLB, the central bank cannot reduce its nominal interest rate to offset the deflationary pressure.
} 
Figure 10. The Effect of Multiperiod Recession at the ZLB in Eggertsson (2011)

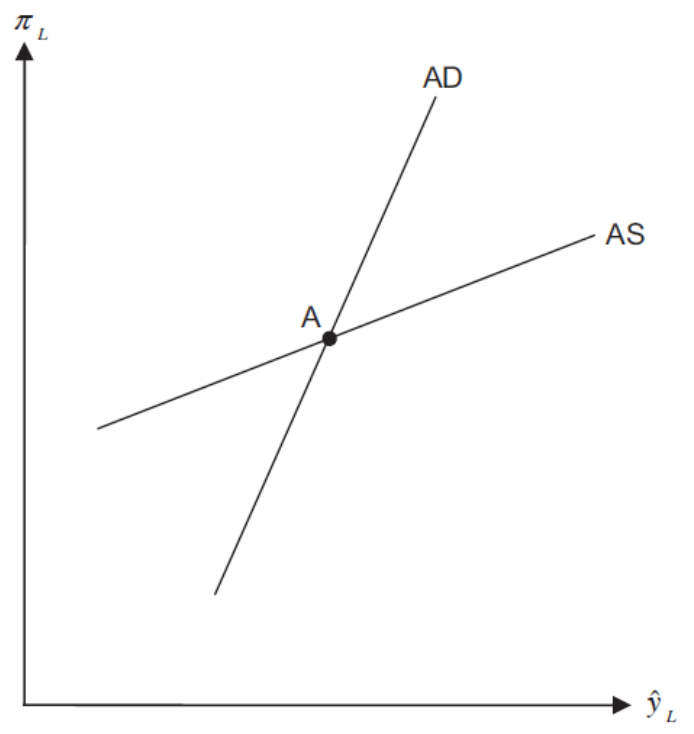

D.1. Why the AD curve is steeper than the AS curve. Rewriting the AD and AS equations in D.2 and D.3 and solving for $\pi_{L}$ gives:

$$
\begin{gathered}
A D^{\prime} \quad \pi_{L}=\frac{(1-\mu) \hat{Y}_{L}}{\sigma \mu}-\frac{r_{L}^{e}}{\mu} \\
A S^{\prime} \quad \pi_{L}=\frac{\kappa \hat{Y}_{L}}{(1-\beta \mu)}
\end{gathered}
$$

If the slope coefficients of the AD and AS curves are the same, both curves are parallel. Eggertsson calls this a deflationary black hole:

$$
\frac{1-\mu}{\sigma \mu}=\frac{\kappa}{1-\beta \mu} \text { or }(1-\beta \mu)(1-\mu)=\sigma \mu \kappa .
$$

In this case no solution exists. For a liquidity trap equilibrium to exist, the following has to hold:

$$
(1-\beta \mu)(1-\mu)>\sigma \mu \kappa .
$$

This is satisfied for a sufficiently low probability $\mu$ of staying at the ZLB. When $\mu$ increases, the AD curve becomes flatter and the AS curve steeper. Eggertsson (2011) assumes $\mu$ to be small enough so that the deflationary black hole does not occur.

D.2. Identification of the demand and supply shocks. The usual identification strategy for demand and supply shocks does not hold if the nominal interest rate is at the ZLB. We briefly outline important aspects of how aggregate demand and supply shocks are identified as well as passed through in the Eggertsson (2011) model.

For identifying the demand from the supply shock at the ZLB, we use the Eggertsson assumption that the $\mathrm{AD}$ curve is steeper than the AS curve. Therefore, a positive demand 
shock increases output gap more than inflation. Vice versa for a positive supply shock. The sign restrictions in Table 1 capture this aspect by restricting the ratio of the output and inflation variables to be larger than one in absolute terms for the demand shock. The opposite holds for the supply shock. Furthermore, a positive demand shock is restricted to increase output and inflation (Figure 11a), whereas a positive supply shock is defined to decrease both variables (Figure 11b).

Figure 11. Aggregate Business Cycle Shocks

(A) Demand Shock

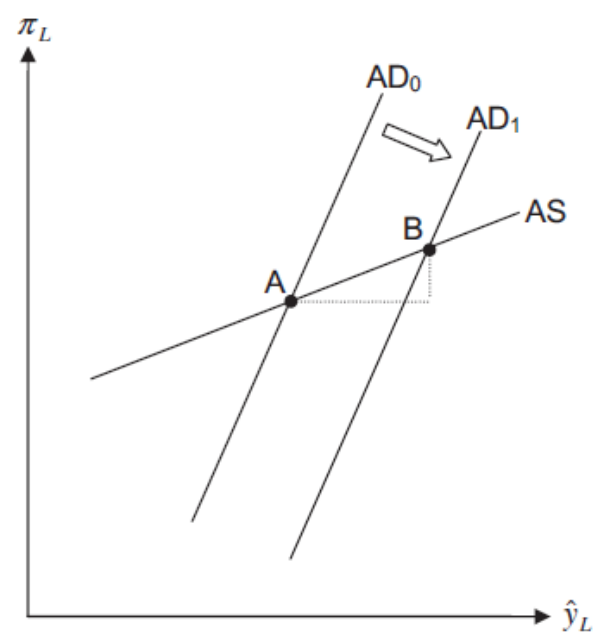

(B) Supply Shock

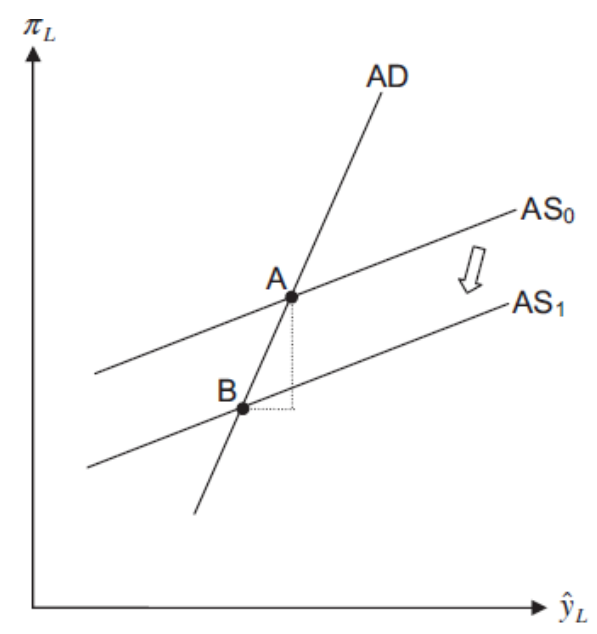

D.3. Effects of a credible expansion of monetary policy at the ZLB. Eggertsson (2011) models a monetary expansion as an increase in future money supply. Monetary policy is assumed to follow:

$$
i_{t}=\max \left\{0, r_{t}^{e}+\pi^{*}+\phi_{\pi}\left(\pi_{t}-\pi^{*}\right)+\phi_{Y}\left(\hat{Y}_{t}-\hat{Y}^{*}\right)\right\}
$$

where $\pi^{*}$ denotes the inflation target and the long run output target is given by $\hat{Y}^{*}=(1-$ $\beta) \kappa^{-1} \pi^{*}$. A large $\pi^{*}$ corresponds to a larger future growth rate in money supply. To see the effect of a higher $\pi^{*}$, we rewrite the $\mathrm{AD}$ and $\mathrm{AS}$ equations for the recession state when the ZLB is binding:

$$
\begin{array}{cc}
A D^{\prime \prime} & \hat{Y}_{L}=\mu \hat{Y}_{L}+(1-\mu) \hat{Y}^{*}+\sigma \mu \pi_{L}+\sigma(1-\mu) \pi^{*}+\sigma r_{L}^{e} \\
A S^{\prime \prime} & \pi_{L}=\kappa \hat{Y}_{L}+\beta \mu \pi_{L}+\beta(1-\mu) \pi^{*}
\end{array}
$$

If $\pi^{*}=0$ is raised to $\pi^{*}>0$, the $\mathrm{AD}$ curve moves to the right and the AS curve to the left (see Figure 12). An increased inflation target for $t \geq T^{e}$ leads to a fall in the real interest rate in $t<T^{e}$. This in turn increases current consumption and thus stimulates current output. Note that next to higher expected inflation in $t \geq T^{e}$, a higher $\pi^{*}$ also induces a higher inflation rate at all periods in which the ZLB is binding (Figure 12). 
FiguRE 12. Effect of a credible inflation commitment at the ZLB

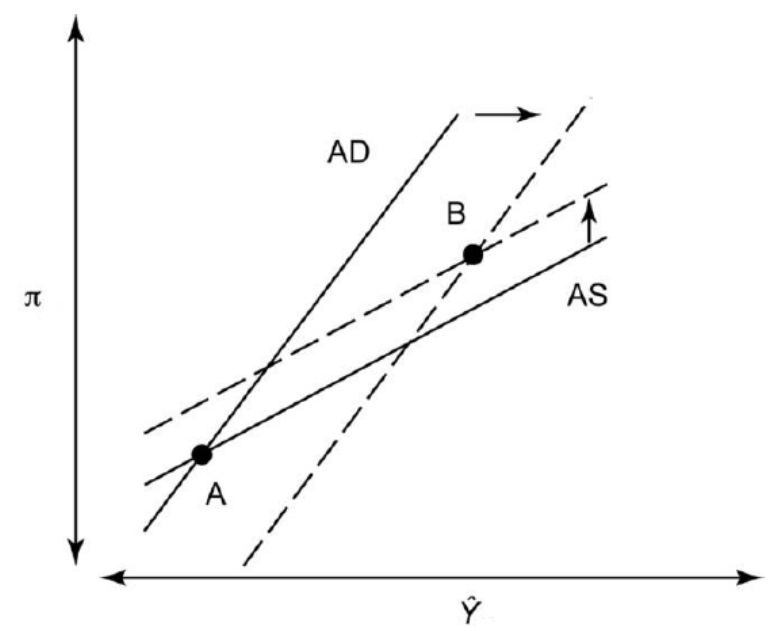

Appendix E. Impulse Responses to a QE Shock at the 4th and 8Th Quarter

Figure 13. Impulse Responses at Different Horizons

(A) Responses at the 4th quarter to a $\mathrm{QE}$ Shock
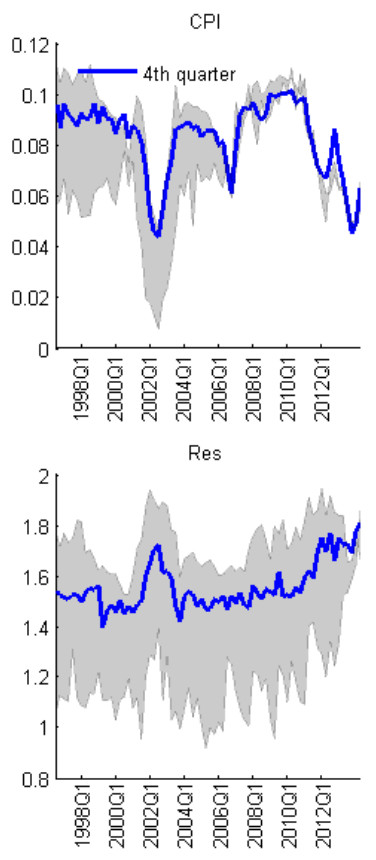
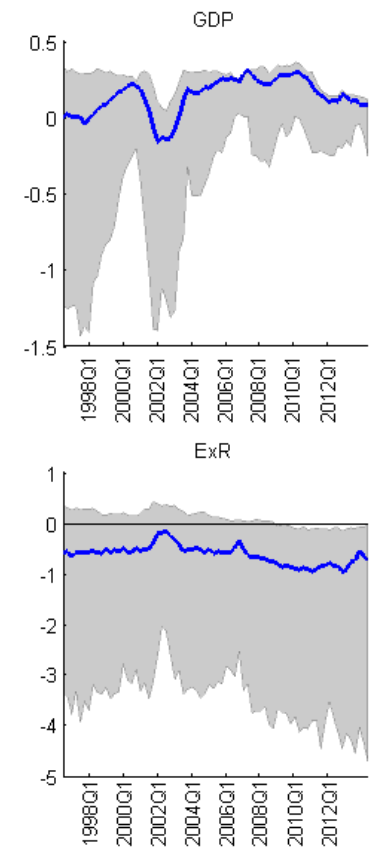

(B) Responses at the 8th quarter to a $\mathrm{QE}$ Shock
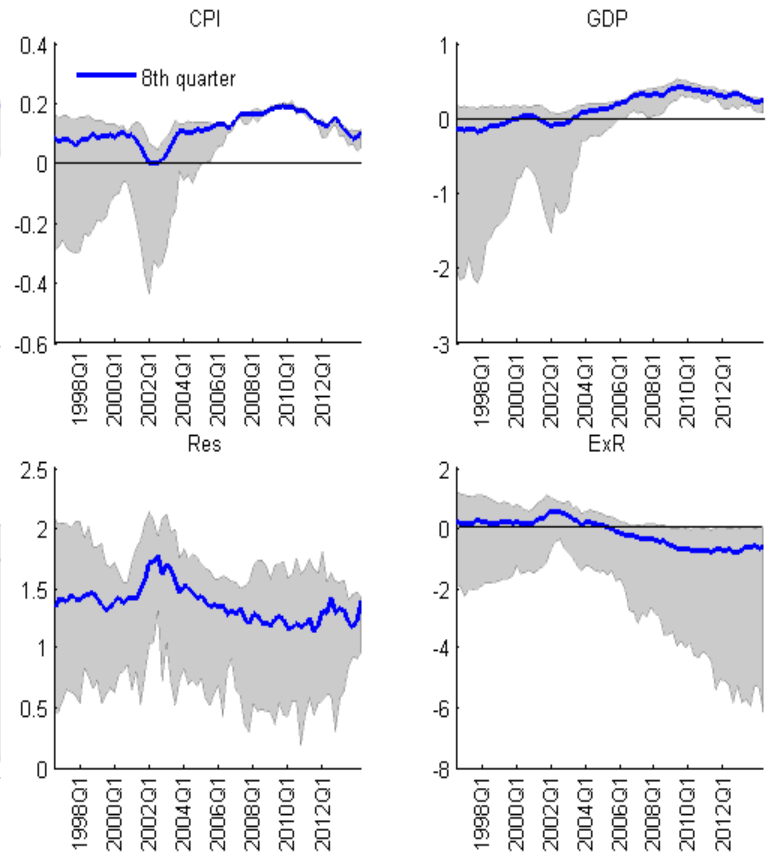

Median impulse responses (blue solid line) to a 1\% QE shock with 16-th and 84-th percentiles (grey area) of the posterior distribution of the responses at the 4th and 8th quarter, respectively. 
Appendix F. Average of the QE Shock for ZIRP, QE- And 'Abenomics' program Figure 14. Responses at Different Time Periods to a QE Shock

(A) Responses without Percentiles
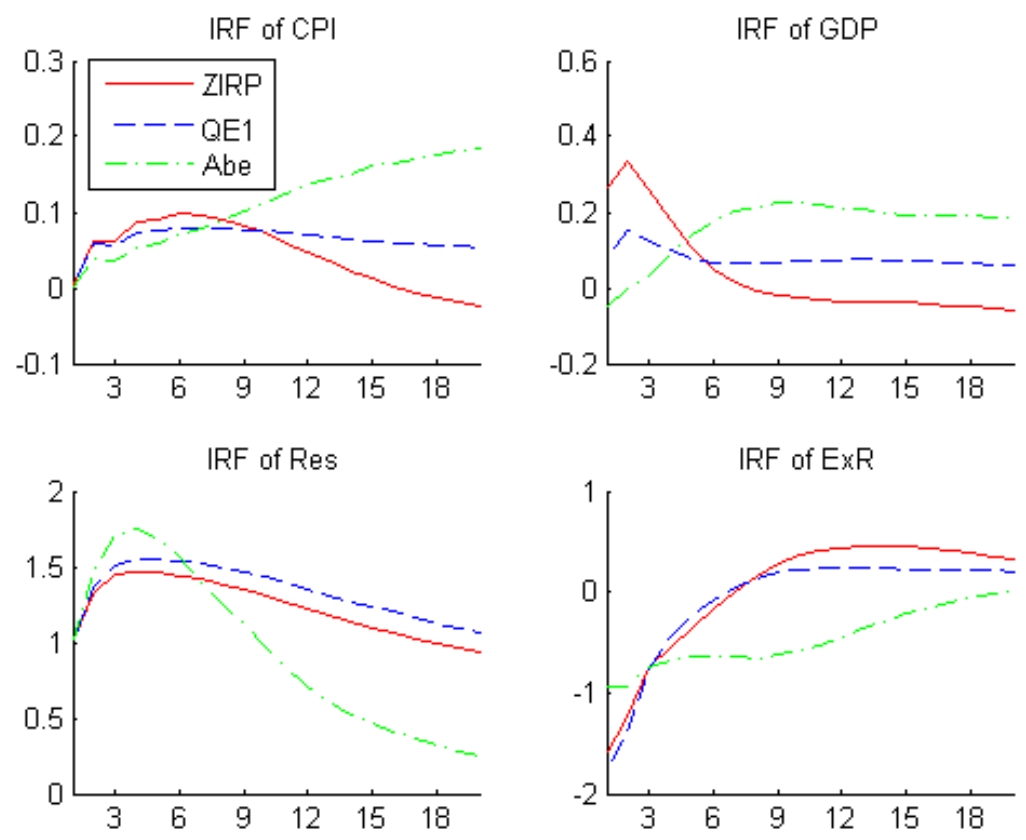

Average of the median impulse responses to a $1 \%$ QE shock during ZIRP, first QE- and 'Abenomics' program.

(в) Responses with Percentiles
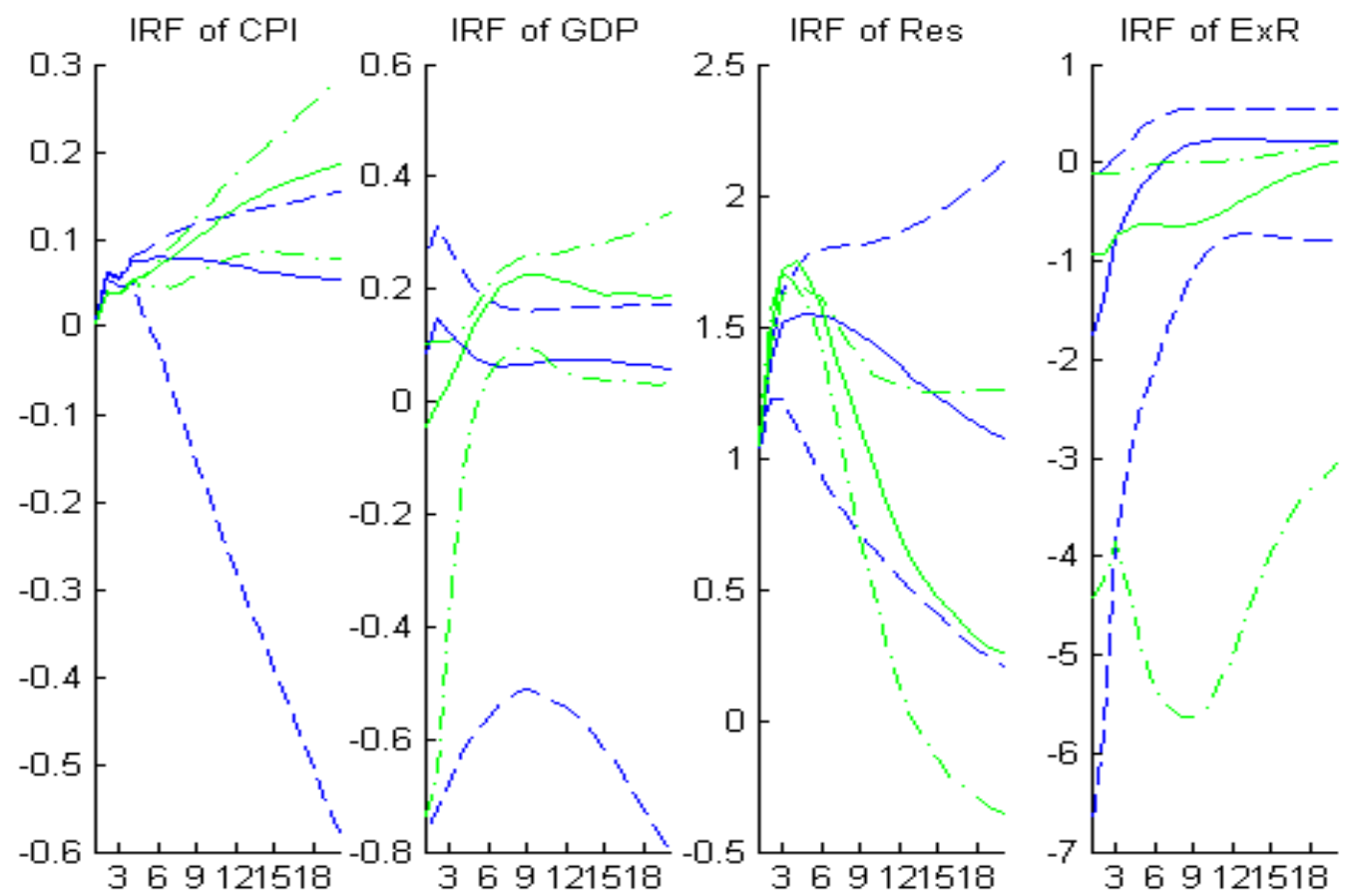

Average of the median impulse responses (solid line) to a 1\% QE shock with 16-th and 84-th percentiles (dashed line) of the posterior distribution during the first QE- and 'Abenomics' program. 
Appendix G. Time-Varying Posterior Estimates of the Stochastic Covariance

The time-varying variance-covariance matrix of the residuals is decomposed as $A_{t}^{-1} \Sigma_{t} \Sigma_{t}^{\prime}\left(A_{t}^{-1}\right)^{\prime}$ and comprises two matrices: (1), the time-varying matrix $\Sigma_{t}$ which denotes the diaogonal matrix of the variances of the structural shocks $\varepsilon_{t}$ and (2), the time-varying lower triangular matrix $A_{t}$ which defines the simultaneous relations. The latter is structured as:

$$
A_{t}=\left[\begin{array}{cccc}
1 & 0 & 0 & 0 \\
\alpha_{\pi y, t} & 1 & 0 & 0 \\
\alpha_{\pi r, t} & \alpha_{y r, t} & 1 & 0 \\
\alpha_{\pi e, t} & \alpha_{y e, t} & \alpha_{r e, t} & 1
\end{array}\right]
$$

where $\pi_{t}$ denotes inflation, $y_{t} \mathrm{GDP}, r_{t}$ reserves and $e_{t}$ the exchange rate. More specifically, $\alpha_{r e, t}$ captures the simultaneous impact of a reserves shock on the exchange rate.

Concerning $\Sigma_{t}$, not much time variation is visible. Figure 16 below shows the estimated stochastic volatility of the structural shock on GDP, prices, reserves and the exchange rate. It plots the posterior mean and the 16th and 84th percentile of the standard deviation of the shock. The second matrix, the time-varying simultaneous relations are plotted in Figure 17. The simultaneous effects are clearly time varying for almost every element in this matrix. 
Figure 15. Estimated Stochastic Volatility of the Structural Shocks

FIgURE 16. Volatility of the Structural Shocks
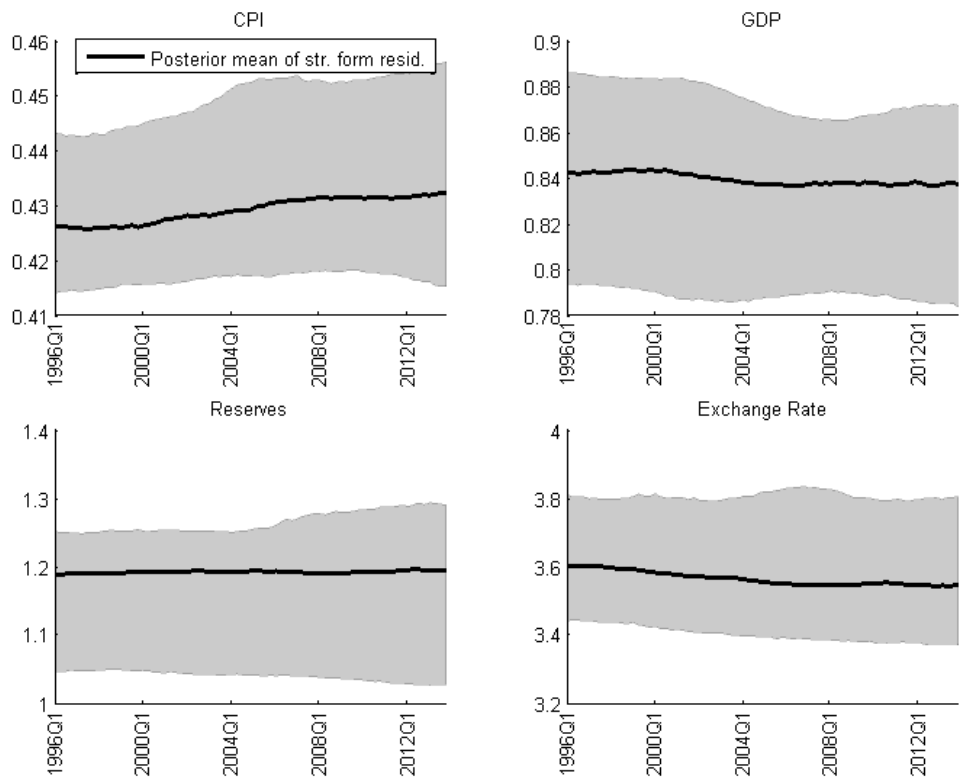

Posterior mean (solid line), 16-th and 84-th percentiles (in grey) of the standard deviation of residuals of the CPI, GDP, reserves and exchange rate equation.

FiguRE 17. Posterior Estimates for the Simultaneous Relation $\tilde{\alpha_{i t}}$
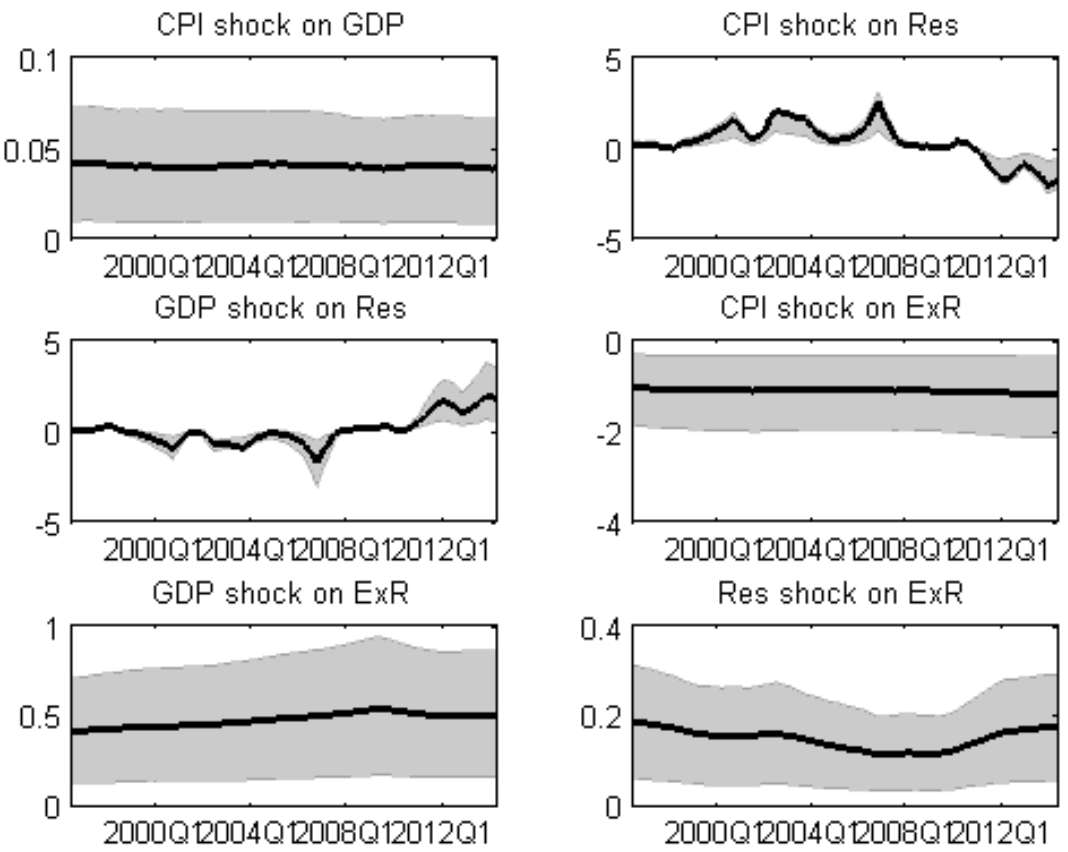

Posterior estimates for the simultaneous relations. Posterior mean (solid line), 16-th and 84-th percentiles (in grey). 
Appendix H. Impulse Responses to a Demand and Supply Shock

\section{H.1. Demand Shock.}

Figure 18. Responses at Different Time Periods to a DE Shock

(A) Responses without Percentiles
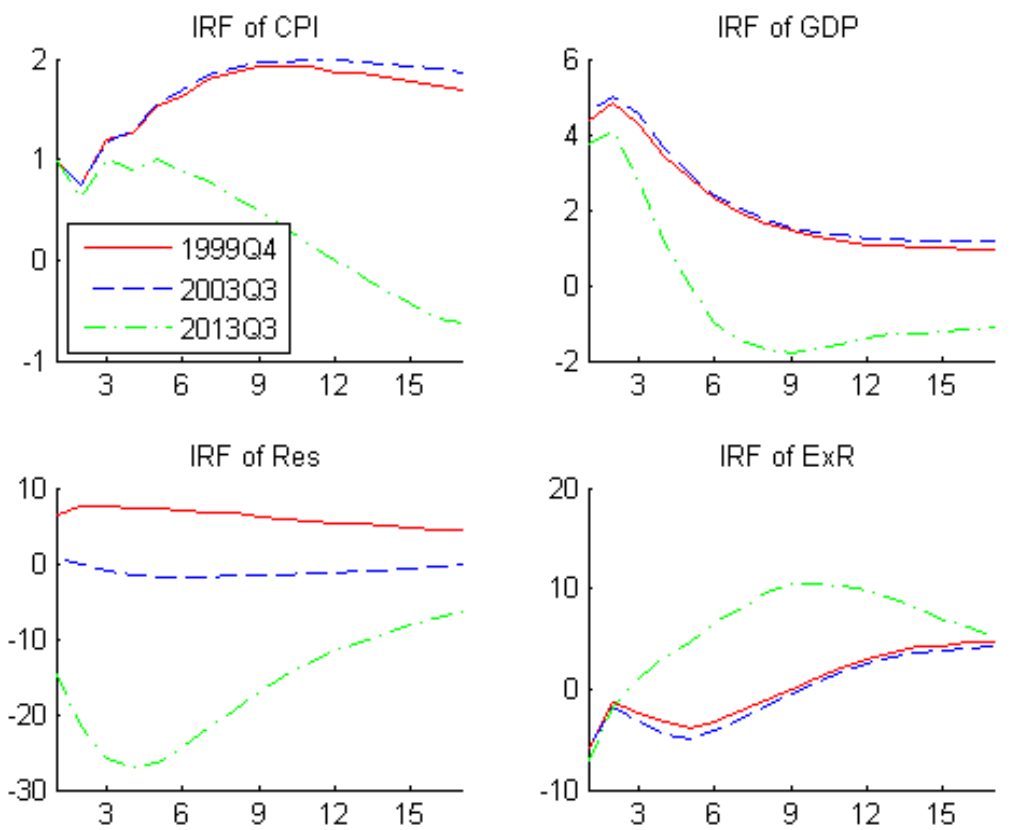

Median impulse responses to a 1\% DE shock at 1999Q4, 2003Q3 and 2013Q3.

(B) Responses with Percentiles
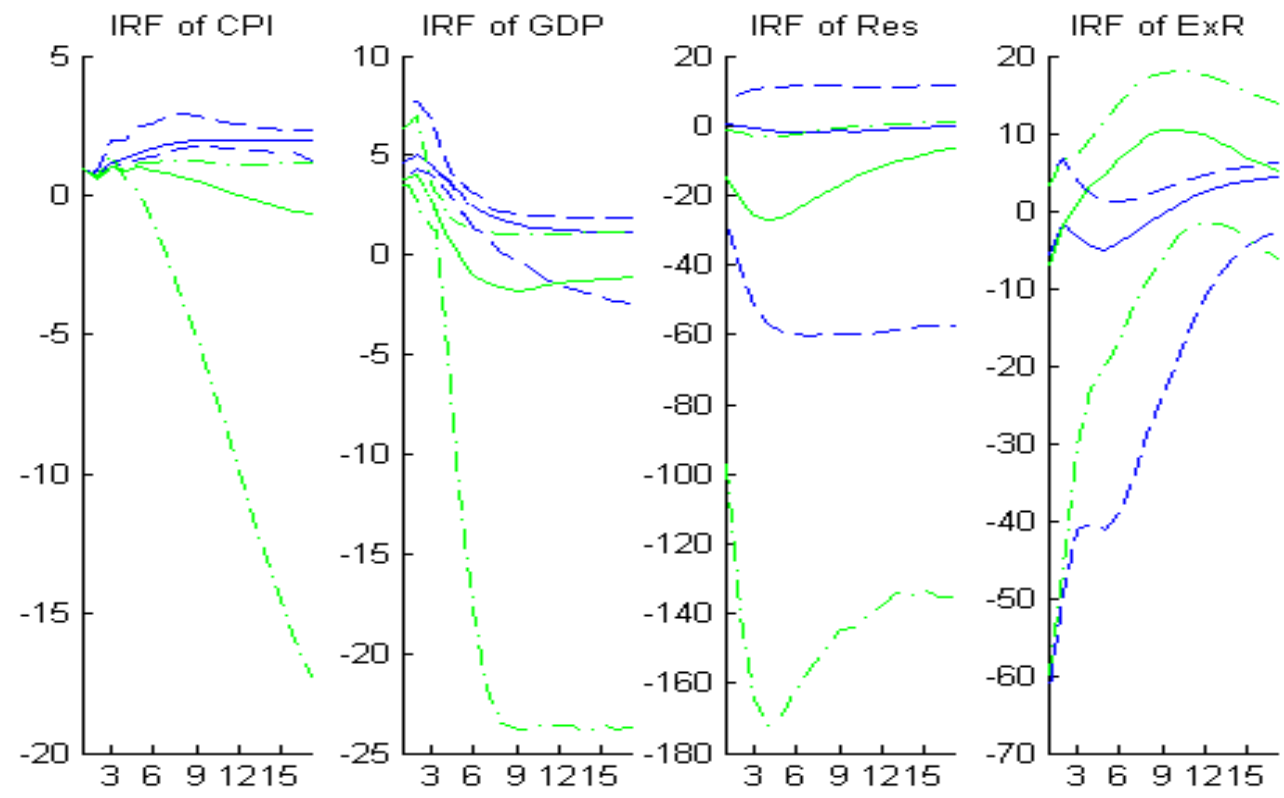

Median impulse responses (solid line) to a 1\% QE shock with 16-th and 84-th percentiles (dashed line) of the posterior distribution at 2003Q3 (blue) and 2013Q3 (green). 


\section{H.2. Supply Shock.}

Figure 19. Responses at Different Time Periods to a SP Shock

(A) Responses without Percentiles
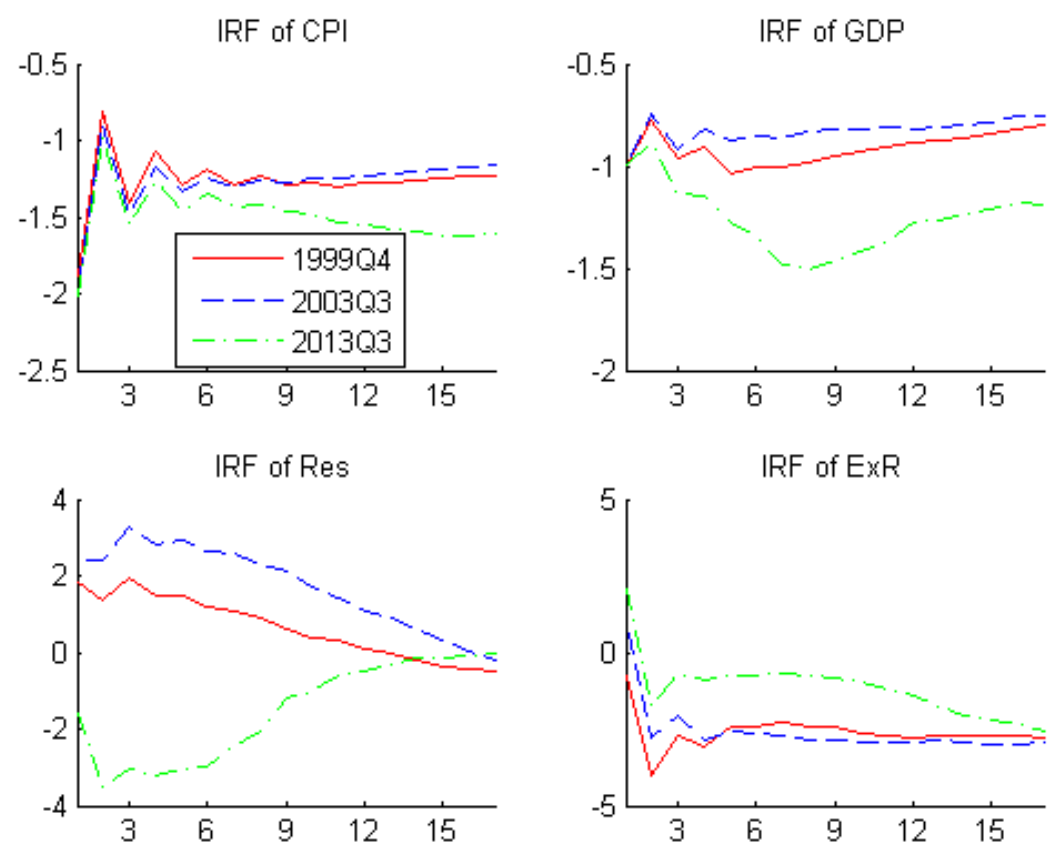

Median impulse responses to a 1\% SP shock at 1999Q4, 2003Q3 and 2013Q3.

(в) Responses with Percentiles
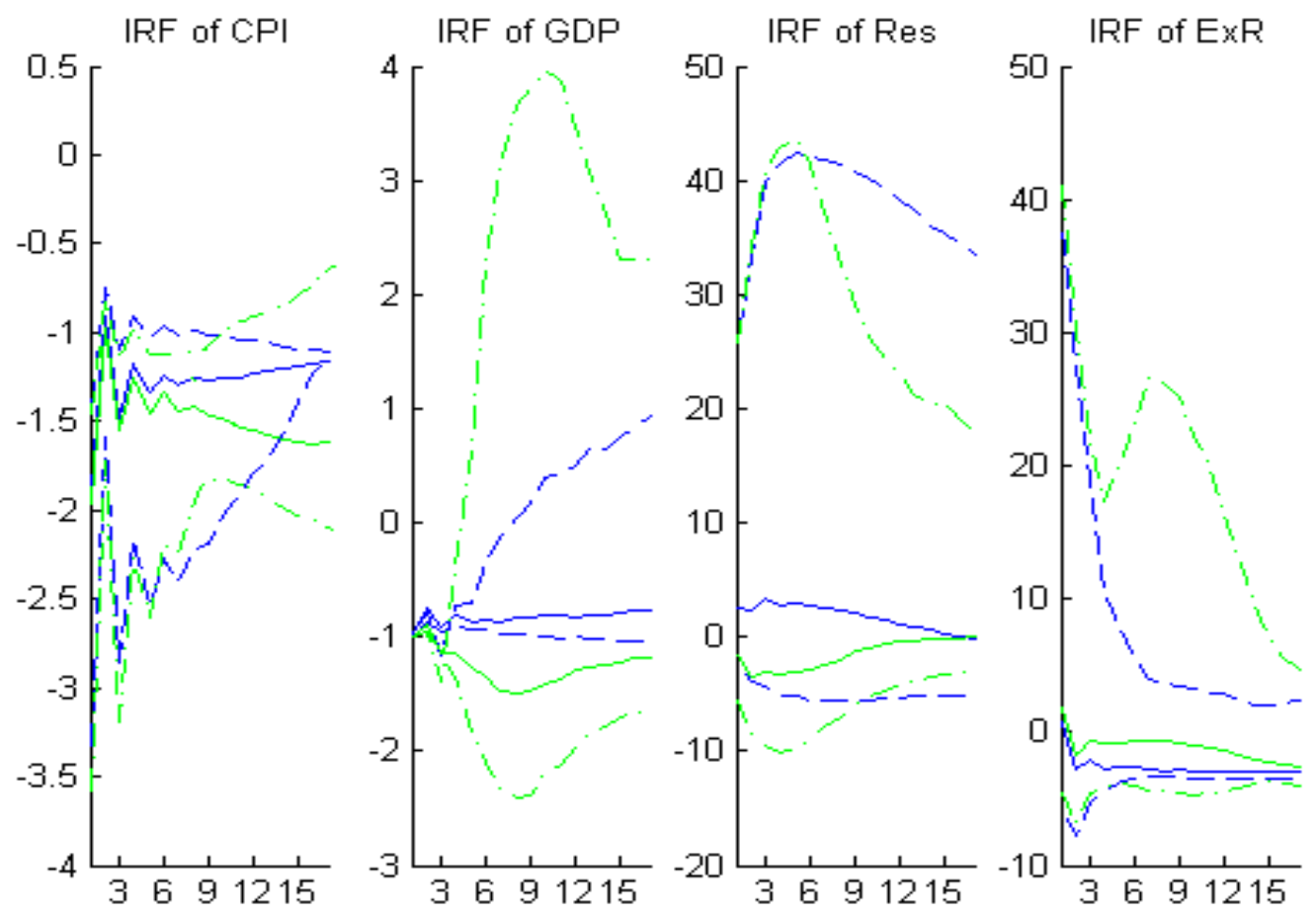

Median impulse responses (solid line) to a $1 \%$ SP shock with 16-th and 84-th percentiles (dashed line) of the posterior distribution at 2003Q3 (blue) and 2013Q3 (green). 
Appendix I. Robustness of the Results

\section{I.1. QE shock based on Close-to-Median Impulse Responses.}

Figure 20. Impulse responses to a QE shock

(A) 1999Q4
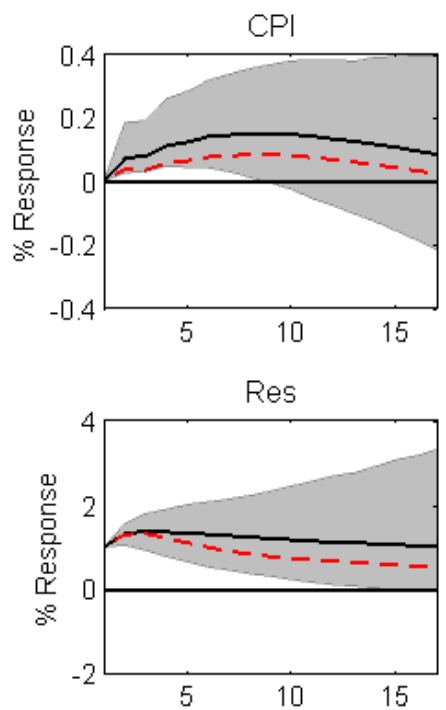
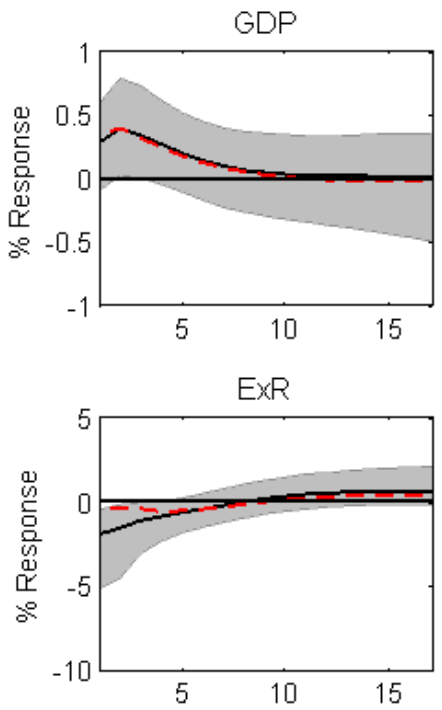

(в) 2003Q3
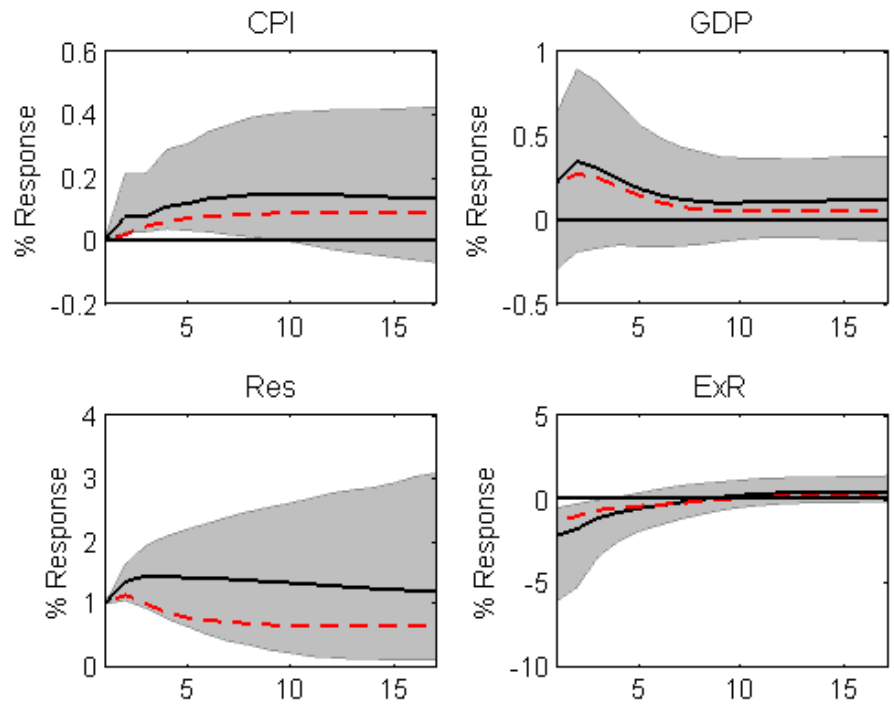

(c) 2013Q3
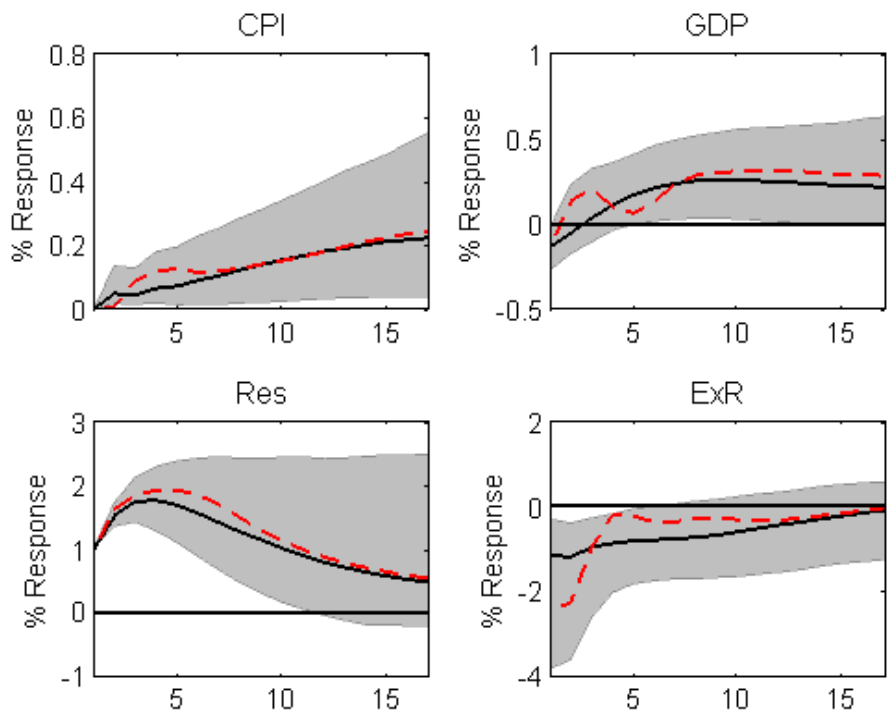

Note: Solid lines denotes the median impulse responses to a 1\% QE shock, grey area the 16-th and 84-th percentiles of the posterior distribution of the responses. The red dashed lines plot the responses based on the close-tomedian model. 


\section{I.2. QE shock based on Alternative Identification I.}

Figure 21. Responses at Different Time Periods to a QE Shock

(A) Responses without Percentiles
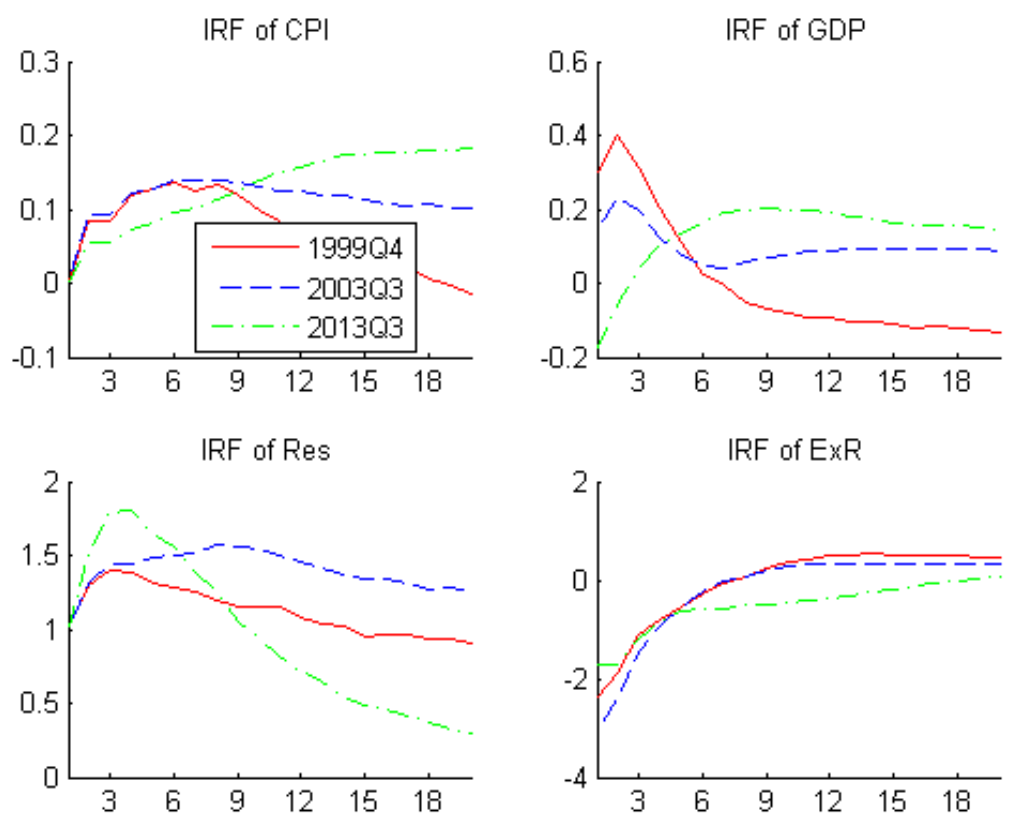

Median impulse responses to a 1\% QE shock at 1999Q4, 2003Q3 and 2013Q3.

(B) Responses with Percentiles

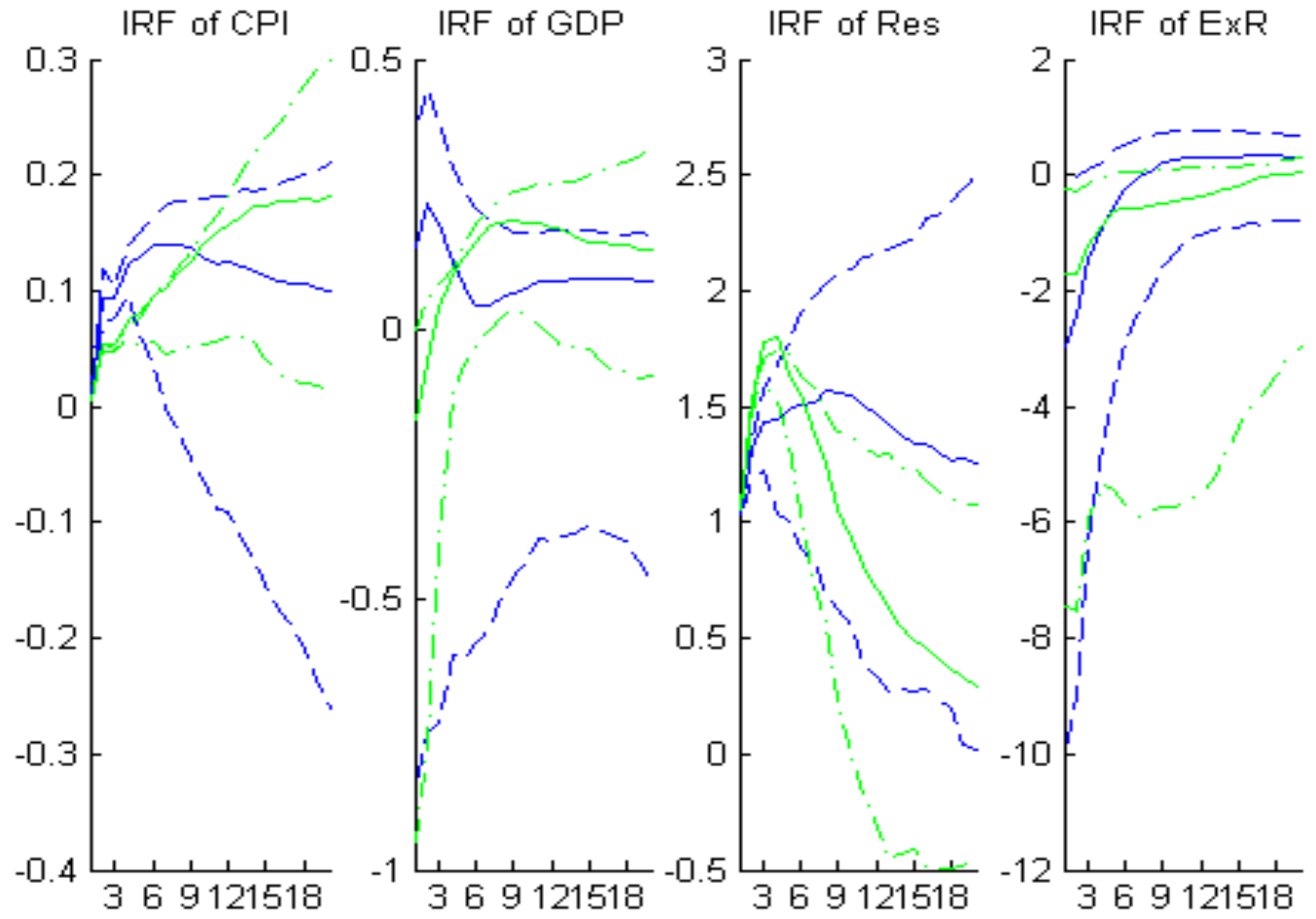

Median impulse responses (solid line) to a 1\% QE shock with 16-th and 84-th percentiles (dashed line) of the posterior distribution at 2003Q3 (blue) and 2013Q3 (green). 


\section{I.3. QE shock based on Alternative Identification II.}

Figure 22. Responses at Different Time Periods to a QE Shock

(A) Responses without Percentiles
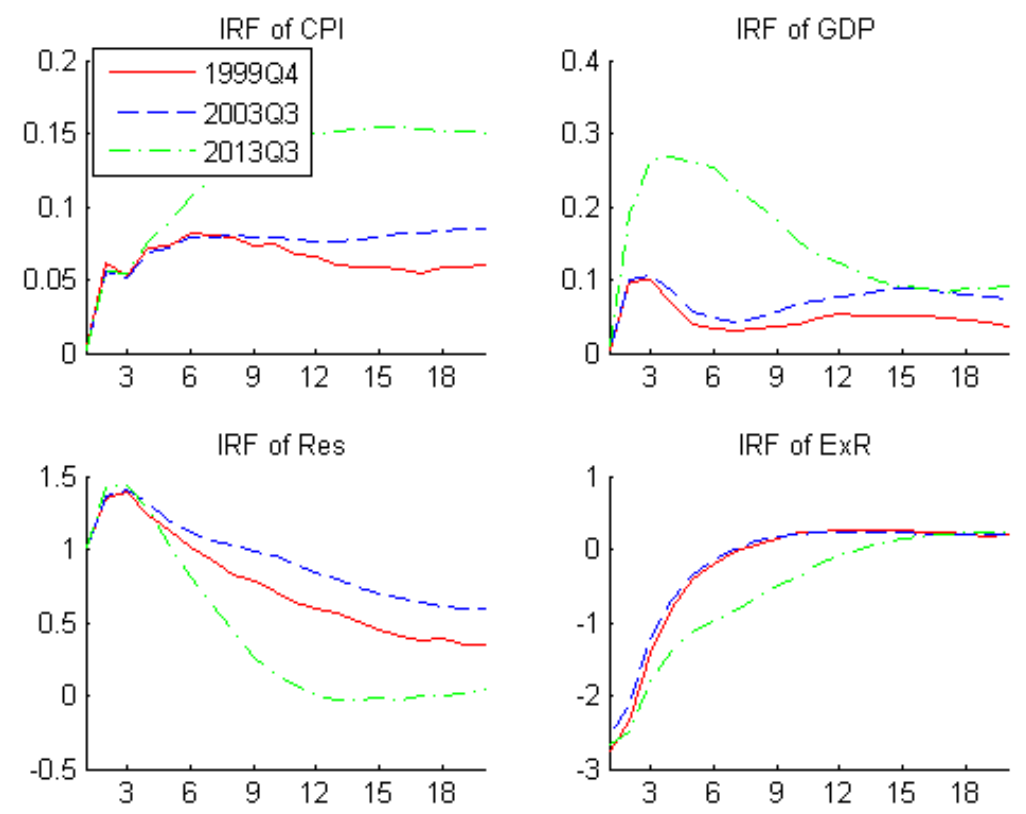

Median impulse responses to a 1\% QE shock at 1999Q4, 2003Q3 and 2013Q3.

(B) Responses with Percentiles
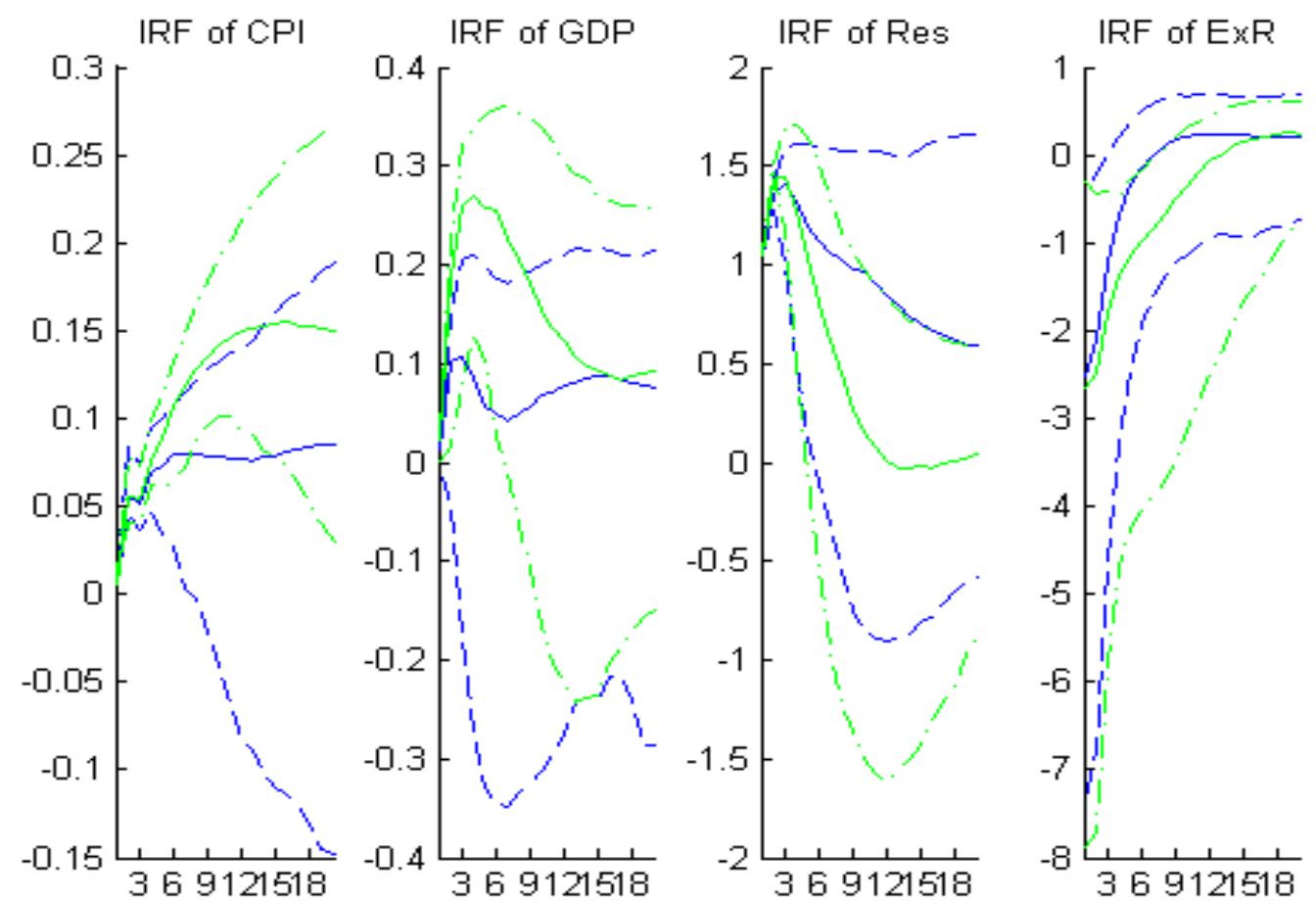

Median impulse responses (solid line) to a $1 \%$ QE shock with 16-th and 84-th percentiles (dashed line) of the posterior distribution at 2003Q3 (blue) and 2013Q3 (green). 


\section{I.4. QE shock based on Alternative Identification III.}

Figure 23. Responses at Different Time Periods to a QE Shock (Cholesky)

(A) Responses without Percentiles
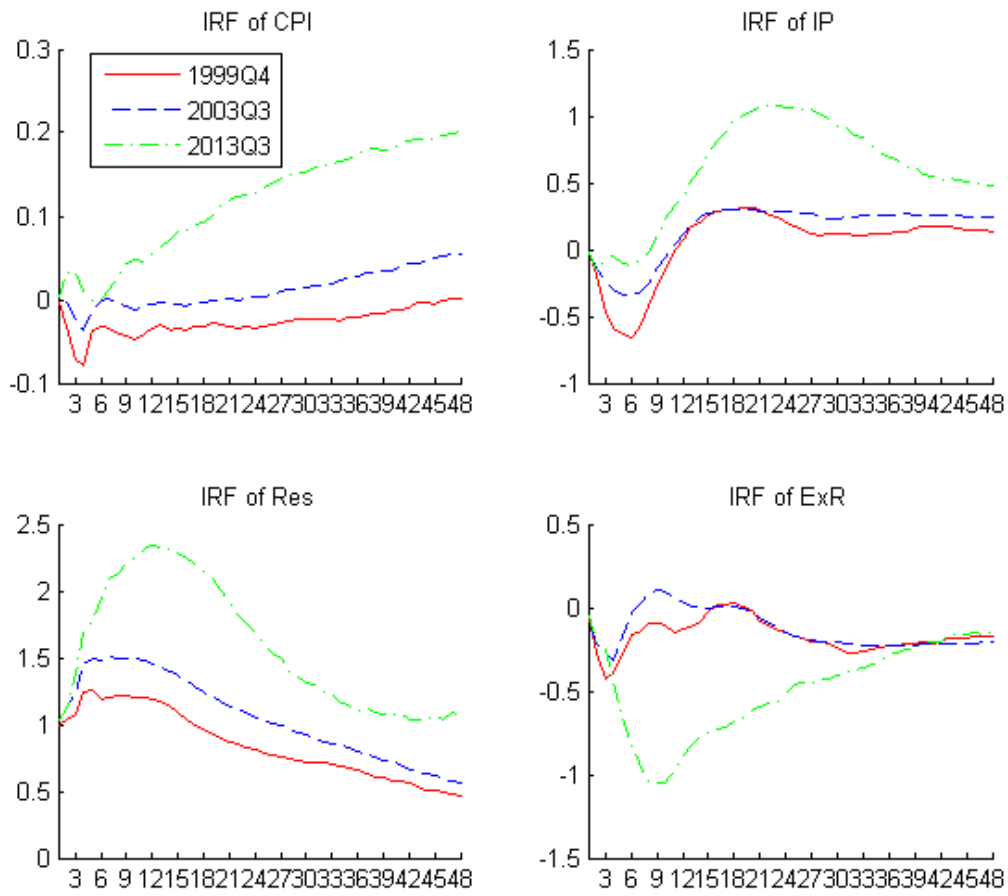

Median impulse responses to a 1\% QE shock at 1999M11, 2003M8 and 2013M8.

(B) Responses with Percentiles
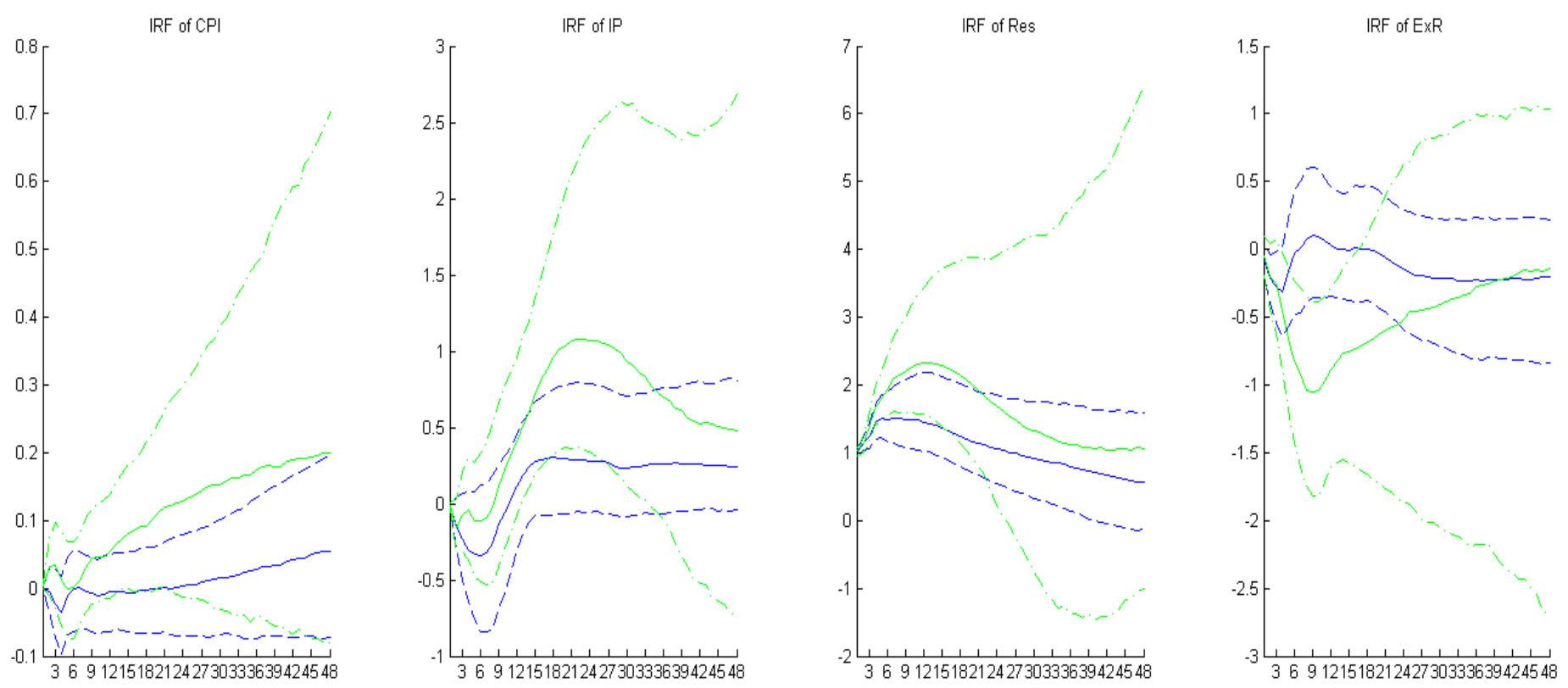

Median impulse responses (solid line) to a $1 \%$ QE shock with 16-th and 84-th percentiles (dashed line) of the posterior distribution at 2003Q3 (blue) and 2013Q3 (green). 


\section{REFERENCES}

Bernanke, B., Reinhart, V., And Sack, B. 2004. Monetary Policy Alternatives at the Zero Bound: An Empirical Assessment. Brookings papers on economic activity 2004:1-100.

Bernanke, B. S. and Reinhart, V. R. 2004. Conducting Monetary Policy at Very Low Short-Term Interest Rates. American Economic Review pp. 85-90.

Canova, F. And CicCarelli, M. 2009. Estimating Multicountry VAR Models. International Economic Review 50:929-959.

Eggertsson, G. B. 2011. What Fiscal Policy is Efective at Zero Interest Rates?, pp. 59-112. In NBER Macroeconomics Annual 2010, Volume 25. University of Chicago Press.

Franta, M. 2011. Identification of Monetary Policy Shocks in Japan using Sign Restrictions within the TVP-VAR Framework. Technical report, Institute for Monetary and Economic Studies, Bank of Japan.

Fujiwara, I. 2006. Evaluating Monetary Policy when Nominal Interest Rates are Almost Zero. Journal of the Japanese and International Economies 20:434-453.

Geweke, J. 1999. Using Simulation Methods for Bayesian Econometric Models: Inference, Development, and Communication. Econometric Reviews 18:1-73.

Hausman, J. K. and Wieland, J. F. 2014. Abenomics: Preliminary Analysis and Outlook. Technical report, mimeo.

Hayashi, F. And Koeda, J. 2014. Exiting from QE. CARF F-Series CARF-F-322, Center for Advanced Research in Finance, Faculty of Economics, The University of Tokyo 12.

Iwata, S. AND Wu, S. 2006. Estimating Monetary Policy Effects when Interest Rates are Close to Zero. Journal of Monetary Economics 53:1395-1408.

Jinushi, T., Kuroki, Y., And Miyao, R. 2000. Monetary Policy in Japan since the late 1980s: Delayed Policy Actions and some Explanations. Japan's Financial Crisis and Its Parallels to US Experience pp. 115-48.

Kamada, K. And Sugo, T. 2006. Evaluating Japanese Monetary Policy under the Nonnegativity Constraint on Nominal Short-Term Interest Rates. The Bank of Japan Working Paper Series p. 17.

Kimura, T., Kobayashi, H., Muranaga, J., And Ugai, H. 2003. The Effect of the Increase in the Monetary Base of Japan's Economy at Zero Interest Rates: An Empirical Analysis, pp. 276-312. In B. for International Settlements (ed.), Monetary policy in a changing environment, volume 19 of BIS Papers chapters. Bank for International Settlements.

Kimura, T. And Nakajima, J. 2013. Identifying Conventional and Unconventional Monetary Policy Shocks: A Latent Threshold Approach. Bank of Japan.

Kirchner, M., Cimadomo, J., and Hauptmeier, S. 2010. Transmission of Government Spending Shocks in the Euro Area: Time Variation and Driving Forces. Tinbergen Institute. 
Krugman, P. 1998. It's Baaack: Japan's Slump and the Return of the Liquidity Trap. Brookings Papers on Economic Activity 2:137-205.

Krugman, P. 2000. Thinking about the Liquidity Trap. Journal of the Japanese and International Economies 14:221-237.

Mikitani, R. And Posen, A. S. 2000. Japan's Financial Crisis and its Parallels to US Experience, volume 13. Peterson Institute.

Miyao, R. 2002. The Effects of Monetary Policy in Japan. Journal of Money, Credit, and Banking 34:376-392.

Nakajima, J. 2011. Time-Varying Parameter VAR Model with Stochastic Volatility: An Overview of Methodology and Empirical Applications. Technical report, Institute for Monetary and Economic Studies, Bank of Japan.

Nakajima, J. And Ginkō, N. 2011. Monetary Policy Transmission under Zero Interest Rates: An Extended Time-Varying Parameter Vector Autoregression Approach. Technical report, Institute for Monetary and Economic Studies, Bank of Japan.

Nakajima, J., Kasuya, M., And Watanabe, T. 2011. Bayesian Analysis of Time-Varying Parameter Vector Autoregressive Model for the Japanese Economy and Monetary Policy. Journal of the Japanese and International Economies 25:225-245.

NakAjima, J. And West, M. 2013. Bayesian Analysis of Latent Threshold Dynamic Models. Journal of Business \&5 Economic Statistics 31:151-164.

Peersman, G. And Straub, R. 2006. Putting the New Keynesian Model to a Test. IMF Working Paper Series 6.

Primiceri, G. 2005. Time Varying Structural Vector Autoregressions and Monetary Policy. Review of Economic Studies 72:821-852.

Schenkelberg, H. And Watzka, S. 2013. Real Effects of Quantitative Easing at the Zero Lower Bound: Structural VAR-based Evidence from Japan. Journal of International Money and Finance .

Sims, C., Stock, J., And Watson, M. 1990. Inference in Linear Time Series Models with Some Unit Roots. Econometrica: Journal of the Econometric Society pp. 113-144.

Ueda, K. 2012. The Effectiveness of Non-Traditional Monetary Policy Measures: The Case of the Bank of Japan. Japanese Economic Review 63:1-22.

Ugai, H. 2007. Effects of the Quantitative Easing Policy: A Survey of Empirical Analyses. Monetary and Economic Studies-Bank of Japan 25:1.

Uhlig, H. 2005. What are the Effects of Monetary Policy on Output? Results from an Agnostic Identification Procedure. Journal of Monetary Economics 52:381-419. 